\title{
First-Principles Plane-Wave-Based Exploration of Cathode and Anode Materials for Li and $\mathrm{Na}$-ion Batteries
}

\author{
Christina Ertural, Ralf P. Stoffel, Peter C. Müller, C. Alexander Vogt, and Richard Dronskowski* \\ KEYWORDS: First-Principles, Density Functional Theory, Plane Waves, Charges, Chemical Bonds, Battery Materials
}

\begin{abstract}
We present a first-principles study based on plane-wave derived Löwdin population analysis and other local bonding descriptors to investigate cathode and anode materials for lithium and sodium ion batteries. By comparing the Löwdin charges of common graphite-based anode materials such as $\mathrm{LiC}_{6}$ and $\mathrm{LiC}_{12}$ to other phases such as salts of dicyanamide and nanoporous carbon-based compounds, new conclusions of an improved intercalation behavior of the latter are derived. In addition, we explore the stability of the dicyanamide salts concerning the removal of Li and Na atoms from the compounds with some of them resulting in dimerized structures. In particular, having a look at the different kinds of bonds and the corresponding covalency indicators reveals new insights into the change of the bonds during dimerization. Considering the generally high thermal stability of metal dicyanamide salts, which are solid at room temperature, their electrochemical activity as well as non-toxicity of alkali metal-based compounds, these materials are potential alternatives to commercially available electrodes, particularly for sodium ion batteries, to pristine graphite-based anode materials.
\end{abstract}

\section{INTRODUCTION}

Exploring and understanding the fundamental processes, also on an atomic scale, in materials containing lithium and sodium ions is the key for developing more efficient batteries. Such rechargeable devices for energy storage, in particular $\mathrm{Li}$ ion batteries, play an increasingly important role in portable electronic devices, such as mobile phones and laptop computers, as well as in electric vehicles. ${ }^{1-9}$ These batteries are desired to be light, inexpensive, easy to maintain, safe and longlived. ${ }^{1,4,5}$ That being said and despite enormous progress, the world has already witnessed serious problems such as catastrophic failure of Li-ion batteries in automotive ${ }^{10}$ and aeronautical ${ }^{11}$ applications, and there is also a growing concern as regards the environmental issues for mining its constituents (say, lithium and cobalt) from developing countries. ${ }^{12,13}$ It may well be the case that present-day battery technology is effectively unsustainable. ${ }^{14,15}$

Nonetheless, given at least a sustainable energy production, whether from fossil fuels, from so-called renewables, or from nuclear power such as breeder/burner technology, thorium reactors, Generation IV, or small modular fission concepts, ${ }^{16}$, 17 improving the current Li-ion battery technology is a topic of paramount importance, and tailoring the properties of cathode and anode materials for their particular field of application is at its very center. As alluded to already, commonly used candidates for such batteries contain lithium and sodium. While the more precious Li exhibits a high gravimetric capacity, the large natural abundance of Na makes it suitable, at least in principle, as a low-cost material, especially for stationary uses.1,18-43 Likewise, K-based batteries are of interest because of low costs and sufficient energy density of the material, although anodes such as $\mathrm{KC}_{8}$ suffer from limited ability of cycling and instability issues. ${ }^{44}, 45$ A more detailed comparison of lithium-, sodium- and potassium-ion batteries can be found in the literature. ${ }^{45-49}$

In batteries, energy is stored electrochemically via a reversible intercalation or conversion reaction involving metal atoms inside electrode materials. As regards the presently far more abundant intercalation batteries, the cathode materials typically consist of metal oxides, silicates, or phosphates while graphite-based compounds are used as anode materials. ${ }^{1}, 7,39,50-54$ In particular, the ternary oxide $\mathrm{LiCoO}_{2}$ is commercially used in Li-ion batteries because of its good intercalation behavior although the toxicity, the cost and the way cobalt is being produced are clear drawbacks so that the development of alternatives containing, say, iron and manganese is pursued.1, 7, 55, 56 For Na-ion batteries, $\mathrm{Na}_{x} M \mathrm{O}_{2}(M=\mathrm{Fe}, \mathrm{Mn})$ cathode materials are widely spread although Na does not go well with graphite. ${ }^{1,57}$ While anode materials for Li-ion batteries typically consist of lithium atoms intercalated into graphite sheets ${ }^{8,50,54,58}\left(\mathrm{LiC}_{6}\right.$ or $\mathrm{LiC}_{12}$ ), for $\mathrm{Na}$-ion batteries nanoporous graphite-type alternatives are needed, since $\mathrm{Na}$ ions do not intercalate into graphite, as said before. . $^{39,54,59-64}$ Here, a conversion reaction between $\mathrm{Na}$ and transition-metal carbodiimides such as FeNCN65, 66 is an attractive alternative, at least in principle. Likewise, nanoporous and nanostructured materials are commonly used in Li- and Na- ion batteries to enhance the electrode performance because they can be understood as intermediates between amorphous and crystalline materials. ${ }^{7,8,60}$

As regards computational materials design, a number of different methods ${ }^{67-70}$ have been used to study the properties of electrode materials for metal ion batteries, among them molecular dynamics (MD) and density functional theory (DFT).${ }^{71-77}$ Although there can be hardly any doubt as regards the suitability of these approaches, some challenges still must be faced when describing properties such as band gap and 
redox potentials from first principles, in particular for materials containing transition metals (TM). For an improved description of strong $d$-electron correlation in the latter, a simple Hubbard $U$ correction can be used within DFT, and this procedure is commonly dubbed as the DFT $+U$ method, $1,65,78-$ ${ }^{80}$ with often stunningly good success, as seen later.

In this work, we aim to show the potential of a recently developed tool for the analytical projection of Löwdin ${ }^{81}$ (and Mulliken $^{82}$ ) charges from plane wave calculations, ${ }^{83-85}$ namely by applying it to commonly known anode and cathode materials for $\mathrm{Li}$ - and $\mathrm{Na}$-ion batteries. In addition, several other and chemical related materials such as $\mathrm{Li}$ and $\mathrm{Na}$ dicyanamide salt-like compounds and carbonic nanoporous systems were examined as they are compelling candidates for the application as electrode materials. ${ }^{8,54,60,62,65,66,86-90}$ The orbitalbased population analyses have been implemented in the Local Orbital Basis Suite Towards Electronic-Structure Reconstruction (LOBSTER) code, ${ }^{85,91,92}$ a program to project PAW functions onto auxiliary local basis sets of contracted all-electron Slater type orbitals and thereby regain chemical information. Its suitability has been recently demonstrated for Zintl phases and polar intermetallics, ${ }^{83}$ phase change materials, ${ }^{93,}, 94$ divalent $3 d$ transition-metal carbodiimides $M N C N(M$ $=\mathrm{Cr}-\mathrm{Cu})^{89}$ as well as regarding the intercalation behavior of $\mathrm{Li}$ and $\mathrm{Na}$ in several nanoporous carbon anode metrials. ${ }^{8,54,85}$ In that work, 83 a comparison was made as regards Mulliken and Löwdin population analysis with Bader's ${ }^{95-100}$ charge analysis. The advantages in using an orbital-based approach within reciprocal space are an enhanced computational efficiency and chemically reliable charges. Additionally, planewave based Mulliken and Löwdin population analyses, as implemented in LOBSTER, are effectively basis-set independent. ${ }^{83}$

\section{COMPUTATIONAL DETAILS}

To start with, we investigated three standard materials presently used in commercially available rechargeable batteries: $\mathrm{LiCoO}_{2}$, $\mathrm{LiFePO}_{4}$, and $\mathrm{NaFePO}_{4}$, as well as the delithiated/desodiated counterpart $\mathrm{CoO}_{2}$, andFePO 4 . Their crystal structures (lattice parameters and atomic positions) were computationally optimized using the projector augmentedwave (PAW) method, as implemented in the Vienna $A b$ initio Simulation Package (VASP). ${ }^{101-105}$ The generalized gradient approximation (GGA) as parametrized by Perdew, Burke, and Ernzerhof (PBE) ${ }^{106}$ was used to model correlation and exchange. In addition, the Hubbard $U$ correction was employed for a better description of the $3 d$ electronic correlation in the transition metals (Co, Fe), taking the $U$ parameter values from the literature. ${ }^{78}$ For the $\mathrm{Co}^{3+}$ species, a $U$ parameter of $4.91 \mathrm{eV}$ was taken whereas $3.71 \mathrm{eV}$ was used for $\mathrm{Fe}^{2+}$, as described in the literature. ${ }^{78}$ Figure S1 in the SI shows the comparison of the density of states for the three cathode materials with and without $U$ parameter. Including $U$ improves the match with the experimental band gaps. ${ }^{107-109}$ For comparing different magnetic states, all calculations for $\mathrm{LiCoO}_{2}, \mathrm{LiFePO}_{4}$ and $\mathrm{NaFePO}_{4}$ were carried out without spin polarization (nonmagnetic, NM) as well as spin-polarized with ferromagnetic (FM, all transition-metal ions with high spin) and antiferromagnetic (AFM) ordering with alternating half of the ions with opposite spin orientation. Experimentally, $\mathrm{LiCoO}_{2}$, $\mathrm{LiFePO}_{4}$ and $\mathrm{NaFePO}_{4}$ have been described as being antiferromagnetic. ${ }^{78,110-113}$ Because the calculated charges ( $c f$. Table S1-S3) of the different magnetization models are close to each other, only the results for the $\operatorname{AFM}(+U)$ model are presented, matching the experimental findings.

In the case of the dicyanamide salts $\mathrm{Li}\left[\mathrm{N}(\mathrm{CN})_{2}\right], \mathrm{Na}\left[\mathrm{N}(\mathrm{CN})_{2}\right]$, $\mathrm{LiCs}_{2}\left[\mathrm{~N}(\mathrm{CN})_{2}\right]_{3}, \mathrm{NaCs}_{2}\left[\mathrm{~N}(\mathrm{CN})_{2}\right]_{3}$, and the tricyanomelaminate salt $\mathrm{Na}_{3}\left[\mathrm{~N}(\mathrm{CN})_{2}\right]_{3}$, van-der-Waals corrections were included using the DFT-D3 method of Grimme114,115 including BeckeJohnson damping; ${ }^{116}$ the same strategy was used upon $\mathrm{Li} / \mathrm{Na}$ deintercalation of these materials, see text. Phonon calculations were performed (except for $\left.\mathrm{Na}_{3}\left[\mathrm{~N}(\mathrm{CN})_{2}\right]_{3}\right)$ using the Phonopy code ${ }^{117}$ and the ab initio force constant method. The necessary forces were obtained from VASP based on supercells with cell parameters of at least $15 \AA$. The densities of phonon states were evaluated on dense meshes of reciprocal space points, and the vibrational properties were checked for the appearance of imaginary phonon modes; in such a case, structures were reoptimized by applying the eigenvectors of the largest imaginary modes to the respective crystal structures. For $\mathrm{Li}\left[\mathrm{N}(\mathrm{CN})_{2}\right]$ and $\mathrm{Na}\left[\mathrm{N}(\mathrm{CN})_{2}\right]$, this procedure led to dimerized structures, as expected for chemical radicals; the Cs containing structures, however, did not show this behavior.

The experimentally known graphite-intercalated alkalinemetal species $\mathrm{LiC}_{6}, \mathrm{LiC}_{12}, \mathrm{KC}_{8}$, as well as model structures $\mathrm{NaC}_{6}$ and $\mathrm{KC}_{6}$ were structurally optimized using the meta-GGA functional SCAN (strongly constrained and appropriately normed semilocal density functional). ${ }^{118}$ For the nanoporous materials whose structures had been obtained via machinelearning-based simulations $\left(\mathrm{Li}_{12} \mathrm{C}_{194}, \mathrm{Li}_{28} \mathrm{C}_{196}, \mathrm{Li}_{32} \mathrm{C}_{196},{ }^{54}\right.$ and $\mathrm{Na}_{14} \mathrm{C}_{206}{ }^{60}$ ), these structures were directly taken from the literature and used here without additional modification.

For the plane waves, a kinetic energy cutoff of $500 \mathrm{eV}$ for $\mathrm{Na}$ - as well as K- and $600 \mathrm{eV}$ for Li-containing compounds was used. The k-point grids were generated following the Monkhorst-Pack method, ${ }^{119}$ and the corresponding sets can be found in the SI ( $c f$. Table S4). For partial band occupancies, the tetrahedron method with Blöchl's correction was used. Real-space density-based charges according to Bader ${ }^{95-100}$ were calculated as reference values for comparison with wave-function-based Mulliken and Löwdin charges. ${ }^{83,84}$ Static calculations were carried out using VASP, preceding the projection from PAW functions to local orbitals with LOBSTER. 

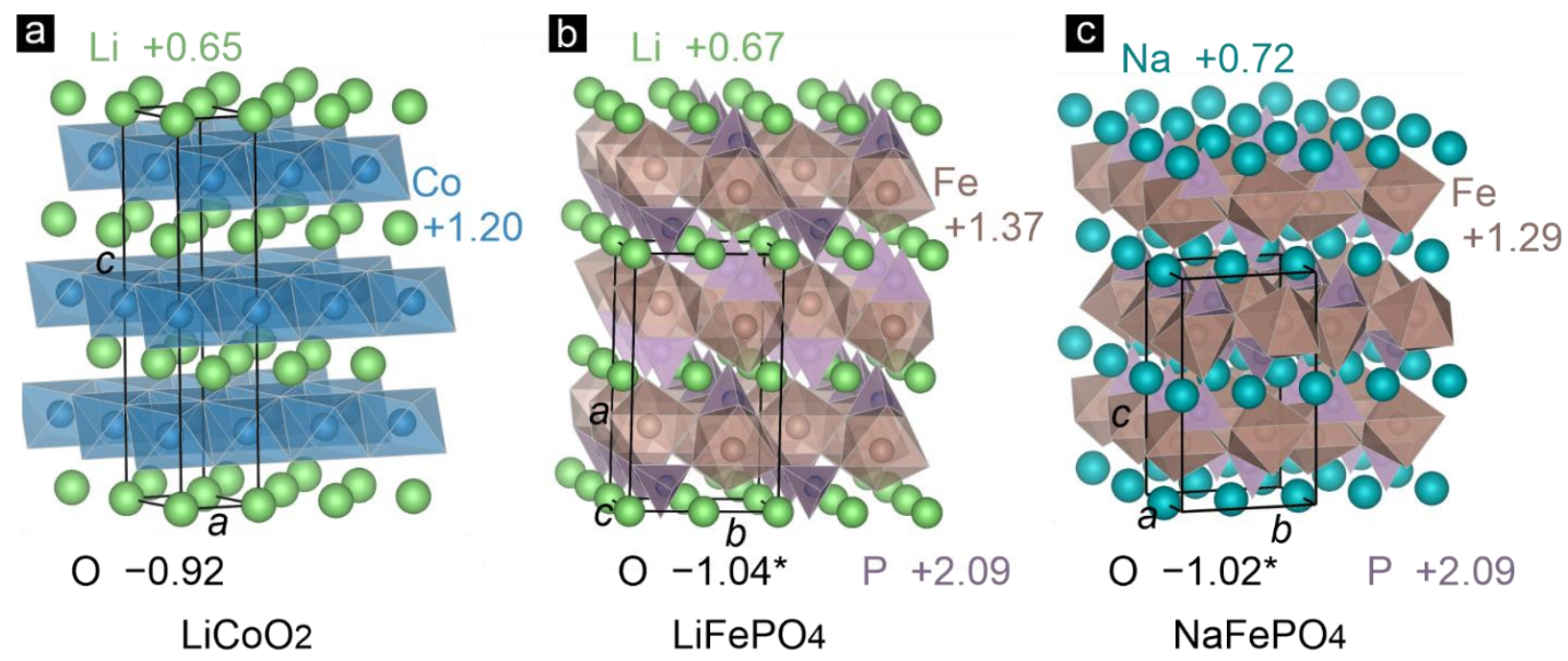

*averaged values

Figure 1. Representations of the crystal structures of a) $\mathrm{LiCoO}_{2}$, b) $\mathrm{LiFePO}_{4}$ and c) $\mathrm{NaFePO}_{4}$. The unit cells are represented with black lines. The $\mathrm{CoO}_{6}$ octahedra are shown in blue, $\mathrm{PO}_{4}$ tetrahedra in violet and $\mathrm{Fe}-\mathrm{O}$ polyhedra in brown, including the respective Löwdin charges.

For determining the activation energies of migration, the total-energy differences of all initial and transition states were calculated. The migration path for $\mathrm{LiCoO}_{2}, \mathrm{LiFePO}_{4}, \mathrm{NaFePO}_{4}$, $\mathrm{LiC}_{6}$, and $\mathrm{LiC}_{12}$ were taken from the literature ${ }^{120-129}$ and the ones for $\mathrm{Li}\left[\mathrm{N}(\mathrm{CN})_{2}\right], \quad \mathrm{Na}\left[\mathrm{N}(\mathrm{CN})_{2}\right], \quad \mathrm{Na}_{3}\left[\mathrm{~N}(\mathrm{CN})_{2}\right]_{3}$, $\mathrm{LiCs}_{2}\left[\mathrm{~N}(\mathrm{CN})_{2}\right]_{3}$, and $\mathrm{NaCs}{ }_{2}\left[\mathrm{~N}(\mathrm{CN})_{2}\right]_{3}$ were found using the nudged elastic band (NEB) method. ${ }^{130,131}$ The migration paths for the nanoporous structures were selected manually. The supercells ( $c f$. Tab. S5) were only calculated at the $\Gamma$ point.

The projected density of states (pDOS) and projected crystal orbital Hamilton population (pCOHP) plots were visualized using the software wxDragon. ${ }^{132}$

\section{RESULTS AND DISCUSSION}

A quick literature search reveals that local-orbital analytic techniques have already been used before for $a b$ initio properties of carbonic anode materials for metal ion batteries. ${ }^{54,60}$ 85,133 In this work, we look at a few more such examples as well as cathode materials. The reason to focus on Mulliken and Löwdin charge analyses is that the amount of charge transfer and the resulting Coulomb interaction will effectively influence the cycling chemistry, the rate performance of the intercalation and also the functionality (such as the charging process) of the battery itself. ${ }^{46,134}$ It was also found ${ }^{45}$ that the main stabilizing effect in graphite-based anode materials stems from the binding energy, composed of some covalent and mostly ionic contributions.

For cathode materials, the commonly used compounds $\mathrm{LiCoO}_{2}, \mathrm{LiFePO}_{4}$ and $\mathrm{NaFePO}_{4}$, were examined, as said before. As anode materials, we first analyzed simple and commonly used Li-intercalated graphitic compounds like $\mathrm{LiC}_{6}$ and $\mathrm{LiC}_{12}$ and compared them with the model structures $\mathrm{NaC}_{6}$ and $\mathrm{KC}_{6}$ Additionally, we examined presumably candidates for alternative anode materials such as dicyanamide-containing and nanoporous carbon-based phases. Because of being popular in the context of plane-wave calculations, Bader charges were calculated for comparing them with Mulliken and Löwdin charges. We note, once again, that orbital-based Mulliken and Löwdin population analysis is far more economical - in terms of sheer speed by about one order of magnitude ${ }^{83}$ - to achieve as compared to the density-based Bader approach, but we will now show that Mulliken and Löwdin still yield chemically meaningful results when Bader's charge analysis reaches its limits, for example in the case of complex nanoporous compounds of amorphous nature. Because Mulliken populations based non-orthogonalized basis sets are not bound between 0 and 2 for a single orbital, a problem usually considered negligible, ${ }^{82,} 135$ this behavior can be solved by using Löwdin's symmetric orthogonalization. ${ }^{81,135}$ Hence, we will mainly discuss Löwdin charges in this work.

\section{CATHODE MATERIALS: OXIDES AND PHOSPHATES}

While $\mathrm{LiCoO}_{2}\left(R \overline{3} m\right.$, No. 166; Fig. 1a) ${ }^{136}$ crystallizes in a layered structure, both ternary phosphates $\mathrm{LiFePO}_{4}$ and $\mathrm{NaFePO}_{4}$ exhibit the olivine-structure-type (Pnma, No. 62; Fig. 1b,c). ${ }^{113,137}$ In all three compounds the transition-metal ion is octahedrally coordinated by six oxide anions, rather regular in $\mathrm{LiCoO}_{2}$ and somewhat distorted in the olivine structures. Likewise, in all three cases, the charges do not vary significantly upon different magnetization order or with usage of the $U$ parameter ( $c f$. Tab. S1-S3). Only in the case of the iron phosphates, Fe possesses significantly lower charges in the (completely unrealistic) non-spin polarized case than in spinpolarized reality ( $c f$. Tab. S2 and S3). The spin-polarized pDOS for the correct AFM spin arrangements with and without $U$ are depicted in Fig. S1. There is no significant difference between charges obtained from Mulliken's, Löwdin's or Bader's method for $\mathrm{LiCoO}_{2}$. In the case of the other compounds, the Bader charges for $\mathrm{P}$ and 0 with $+3.6 e$ and $-1.4 e$, respectively, are higher than the Mulliken or Löwdin charges being around $+2 e$ and $-1 e$ (cf. Tab. S6). Comparing the three compounds with each other, the olivine-type iron phosphates exhibit 
slightly higher charges for the transition metal, alkali metal and oxygen ions than the respective charges in $\mathrm{LiCoO}_{2}$. Not too surprisingly, the sodium cation is slightly higher charged than lithium, the small difference between $\mathrm{Na}$ and Li fitting well with the Pauling electronegativity which is lower for $\mathrm{Na}$ than for $\mathrm{Li}^{138}$ For a compound with $\mathrm{Li} / \mathrm{Na}$ intercalated into fluorinated graphite, it was found that lower charges on $\mathrm{Li} / \mathrm{Na}$ ion correlate with an improved cycling performance of the metal ion intercalation because of weaker Coulomb attraction. ${ }^{134}$ Thus, the lower charges of $\mathrm{Co}, \mathrm{Li}$ and $\mathrm{O}$ are also in accordance with the experimentally known, good intercalation behavior of $\mathrm{LiCoO}_{2} \cdot{ }^{1,7,55,56}$

\section{ANODE MATERIALS: GRAPHITE-BASED COMPOUNDS}

$\mathrm{LiC}_{6}$ and $\mathrm{LiC}_{12}$ crystallize in space group P6/ $\mathrm{mmm}$ (No. 191; Fig. 2) ${ }^{64,139}$ and are both layered structures consisting of pristine graphite with intercalated lithium cations between the graphene sheets. The structural difference between these two compounds is that $\mathrm{LiC}_{12}$ only contains $\mathrm{Li}$ ions in every second layer of $\mathrm{LiC}_{6}$. Both compounds are commonly used as anode materials in batteries. ${ }^{50,54,58}$
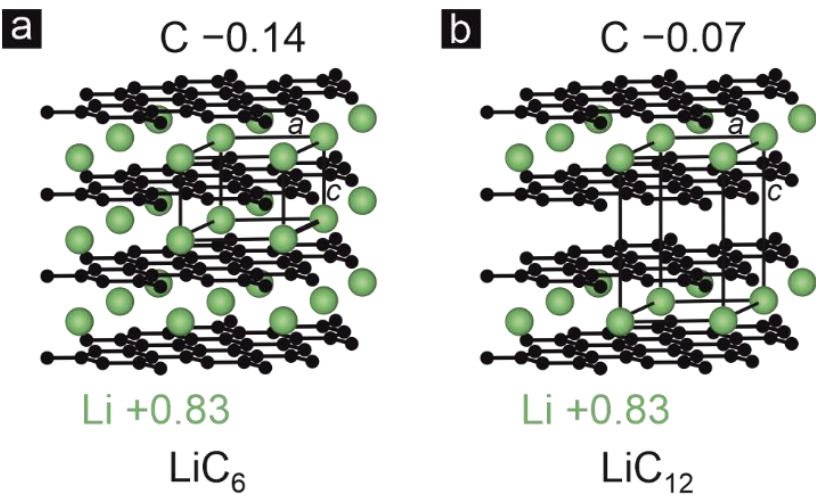

Figure 2. Representations of the crystal structures of a) $\mathrm{LiC}_{6}$ and b) $\mathrm{LiC}_{12}$. The unit cells are represented with black lines. The respective Löwdin charges are shown.

Not surprisingly, Li exhibits exactly the same (Löwdin) charge of $+0.83 e$ in both pristine graphite compounds. The charge transferred from lithium to carbon nicely mirrors that there is only one symmetry-dependent $\mathrm{Li} / \mathrm{C}$ atom, at least in the case of Mulliken and Löwdin charges, so that every carbon atom exhibits $-0.14 e$ and $-0.07 e$ for $\mathrm{LiC}_{6}$ and $\mathrm{LiC}_{12}$, respectively. For some reason, possibly due to the density partitioning and some inaccuracy, the Bader charges scatter quite a lot for the carbon atoms, despite the simple structure, ranging from $-0.05 e$ to $-0.23 e$ for $\mathrm{LiC}_{6}$ and $-0.02 e$ to $-0.14 e$ for $\mathrm{LiC}_{12}$, respectively ( $c f$. Tab. S7 and S8).

As alluded to already, only $\mathrm{Li}$ is known to intercalate into pristine graphite yielding the stable compound $\mathrm{LiC}_{6}$, while $\mathrm{Na}$ does not intercalate in such material at all and $\mathrm{K}$ favors the composition $\mathrm{KC}_{8}$, but still lacking stability. ${ }^{44,45}$ Lenchuk et al. ${ }^{45}$ further investigated this phenomenon and showed that the $\mathrm{LiC}_{6}$ structure, in contrast to the model structures $\mathrm{NaC}_{6}$ and $\mathrm{KC}_{6}$, is stabilized by an additional covalent contribution for $\mathrm{Li}$ in the binding energy, which is not present for $\mathrm{Na}$ or $\mathrm{K}$. Other work $^{46,140}$ hints to the same conclusion. This assumption is easily verified using quantum-chemical analysis and displayed in Fig. 3.

As the metal-carbon bond distance increases from the Li to the Na and eventually to the K compound, the covalency of the bond decreases (as reflected from the IpCOHP values), in perfect accord with chemical knowledge. Clearly, the Li phase stands out in terms of higher covalency. Likewise, the Löwdin charge on the metal also increases in the same order such that the $\mathrm{K}$ phase is the most ionic, also in accord with the course of the electronegativities. For illustration, the Löwdin charge of $\mathrm{K}$ in $\mathrm{KC}_{8}$ is $+0.85 e$, while for $\mathrm{C}$ it is $-0.11 e$ but the integrated project COHP (IpCOHP) for the shortest $\mathrm{K}-\mathrm{C}$ bond (3.04 $\AA$ ) is smallest, namely $-0.07 \mathrm{eV}$. Hence, there is a competition between ionicity and covalency, and the more covalent $\mathrm{Li}-\mathrm{C}$ interaction stands out, in agreement with literature findings. ${ }^{45}$ 46,140

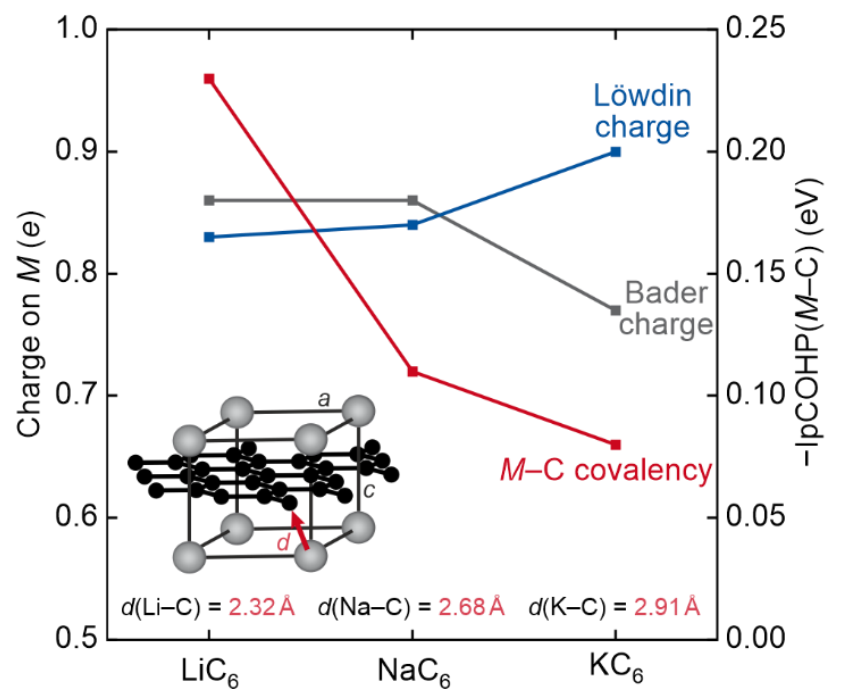

Figure 3. Comparison of Löwdin and Bader charges as well integrated projected COHP (IpCOHP) of $\mathrm{LiC}_{6}, \mathrm{NaC}_{6}$ and $\mathrm{KC}_{6}$.

Puzzlingly, Bader charges arrive at non-chemical values as they suggest the $\mathrm{K}$ phase to be less ionic, in clear conflict with electronegativities. Interestingly and despite being nonchemical, they are comparable with reported Bader charges for $\mathrm{Li}, \mathrm{Na}$ and $\mathrm{K}$ from the literature ${ }^{45}$ with $0.87 e, 0.86 e$ and $0.75 e$, respectively. Like in the case of $\mathrm{LiC}_{6}$, the Bader charges on carbon scatter a lot for $\mathrm{NaC}_{6}$ and $\mathrm{KC}_{6}$ ( $c f$. Tab. S8 in the SI). The Bader charge of $\mathrm{K}$ in $\mathrm{KC}_{8}$ is $+0.82 e$ and scatter for $\mathrm{C}$ from $+0.05 e$ to $-0.25 e$ (also see Tab. S7). 
a

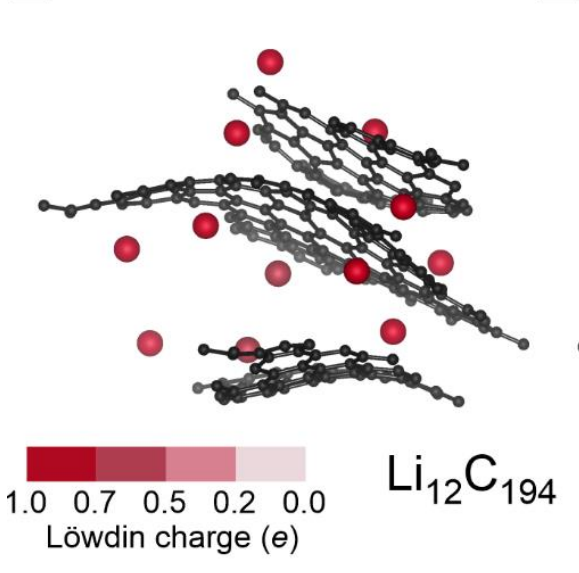

b

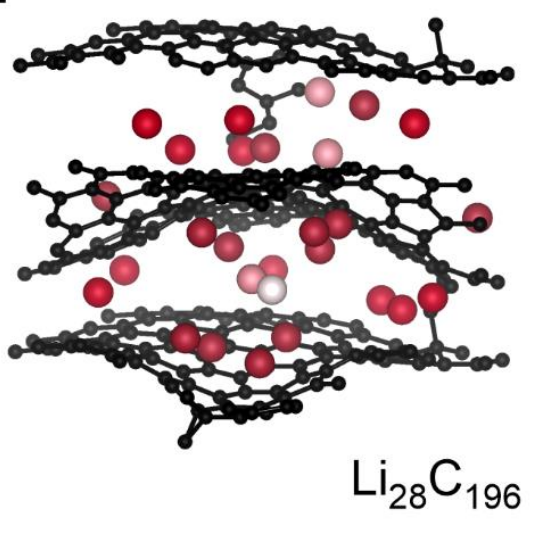

C

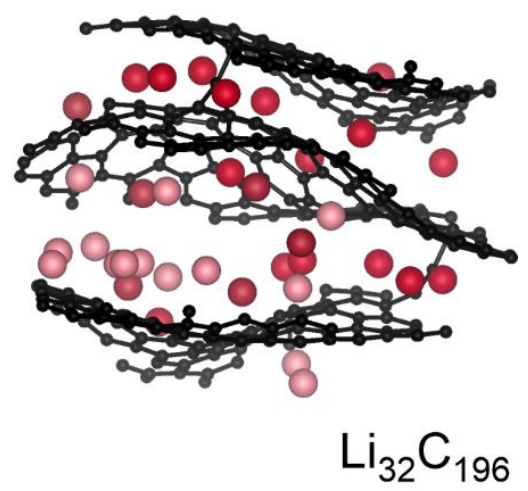

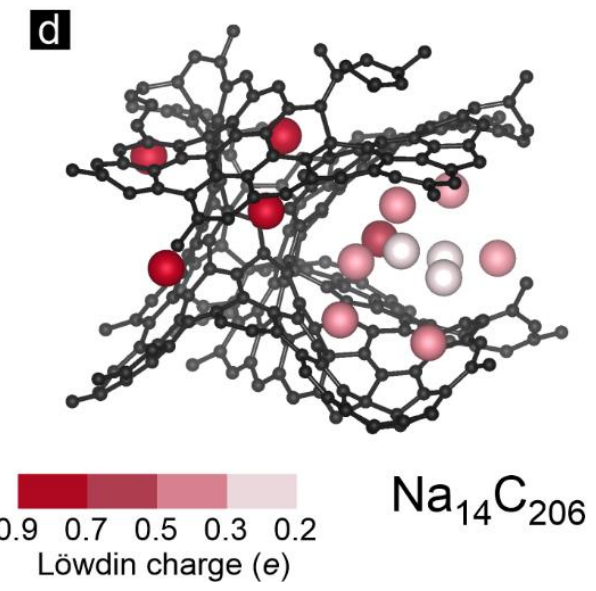

Figure 4. Representations of the crystal structures of a) $\mathrm{Li}_{12} \mathrm{C}_{194}$ b) $\mathrm{Li}_{28} \mathrm{C}_{196}$ c) $\mathrm{Li}_{32} \mathrm{C}_{196}{ }^{54}$ and d) $\mathrm{Na}_{14} \mathrm{C}_{206}{ }^{60}$

\section{NANOPOROUS MATERIALS}

We now move on to amorphous materials. ${ }^{8}$ Huang et al. ${ }^{54}$ and Deringer et al. $^{60}$ presented ways to generate carbonaceous host frameworks of the nanoporous anode materials, such as $\mathrm{Li}_{12} \mathrm{C}_{194}, \mathrm{Li}_{28} \mathrm{C}_{196}, \mathrm{Li}_{32} \mathrm{C}_{196},{ }^{54}$ and $\mathrm{Na}_{14} \mathrm{C}_{206}{ }^{60}$, via a machine-learning-based interatomic potential for carbon, and they optimized these structures after insertion of the metal ions using first principles methods.

Exactly these structures were taken and reused for our study by courtesy of the authors without further modification. The original work on $\mathrm{Na}_{14} \mathrm{C}_{206}$ utilizing Bader charge analysis arrived at negative charges for some of the $\mathrm{Na}$ ions ${ }^{60}$ which contradicts chemical intuition, to say the least. Additionally, based on small-angle X-ray scattering data, an intercalation behavior for nanoporous sodium compounds was proposed that implies the formation of metallic species inside the pores. ${ }^{141,142}$ Operando solid-state NMR measurements on $\mathrm{Li}^{143}$ and $\mathrm{Na},{ }^{144}$ however, evidence that the alkali metal atoms exhibit a cationic or almost metallic character during cycling, but not an anionic one. Negative and generally unreasonable
Bader charges were also found for the MD-simulated compound $\mathrm{Li}_{48} \mathrm{C}_{216}$, whereas Löwdin charge analysis yields positive values only and gave more insight into the structural landscape. ${ }^{54,85}$ To probe if this phenomenon persists for other nanoporous carbon anode compounds, the Bader charges of $\mathrm{Li}_{12} \mathrm{C}_{194}, \mathrm{Li}_{28} \mathrm{C}_{196}, \mathrm{Li}_{32} \mathrm{C}_{196}$ and $\mathrm{Na}_{14} \mathrm{C}_{206}$ were (re)calculated and compared to Löwdin charges obtained by LOBSTER ( $c f$. Tab. S7). For $\mathrm{Li}_{12} \mathrm{C}_{194}$, Löwdin and Bader charges are almost identical. In contrast, for all three $\mathrm{Li}_{28} \mathrm{C}_{196}, \mathrm{Li}_{32} \mathrm{C}_{196}$ and $\mathrm{Na}_{14} \mathrm{C}_{206}$ models, negative Bader lithium charges up to $-1.64 e$ (cf. Tab. S7) are found for those atoms that are known to chemically act as cations.

The Löwdin population analysis, however, delivers chemically plausible charges of +0.63 to +0.91 e for $\mathrm{Li}_{12} \mathrm{C}_{194}$ (Fig. $4 \mathrm{a}$ ), +0.00 to $+0.85 e$ for $\mathrm{Li}_{28} \mathrm{C}_{196}$ (Fig. $4 \mathrm{~b}$ ), and +0.22 to $+0.86 e$ for $\mathrm{Li}_{32} \mathrm{C}_{196}$ (Fig. 4c). The charges on Li decrease with increasing $\mathrm{Li}$ to $\mathrm{C}$ ratio, as expected, so that Li gets more metallic, agreeing with experimental findings. ${ }^{141-144}$ In the case of $\mathrm{Na}_{14} \mathrm{C}_{206}$ (Fig. 4d), Löwdin charges ranging from +0.21 to $+0.85 e$ are found, which are comparable to the charge of $\mathrm{Li}_{32} \mathrm{C}_{196}$. 
a

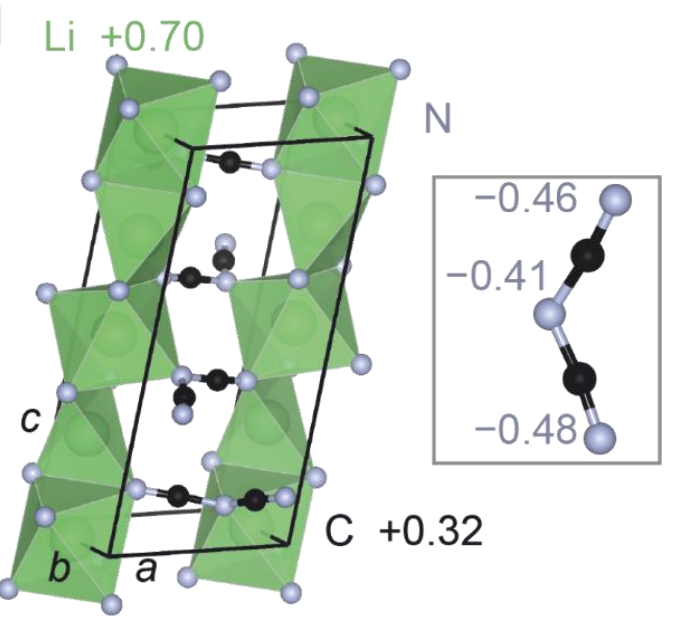

$\mathrm{Li}\left[\mathrm{N}(\mathrm{CN})_{2}\right]$

C

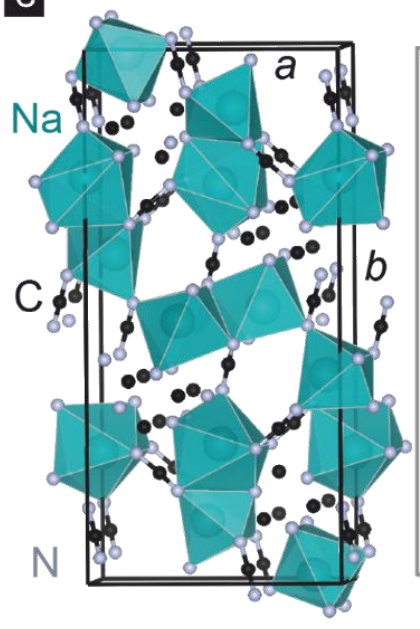

$\mathrm{Na}_{3}\left[\mathrm{~N}(\mathrm{CN})_{2}\right]_{3}$ b

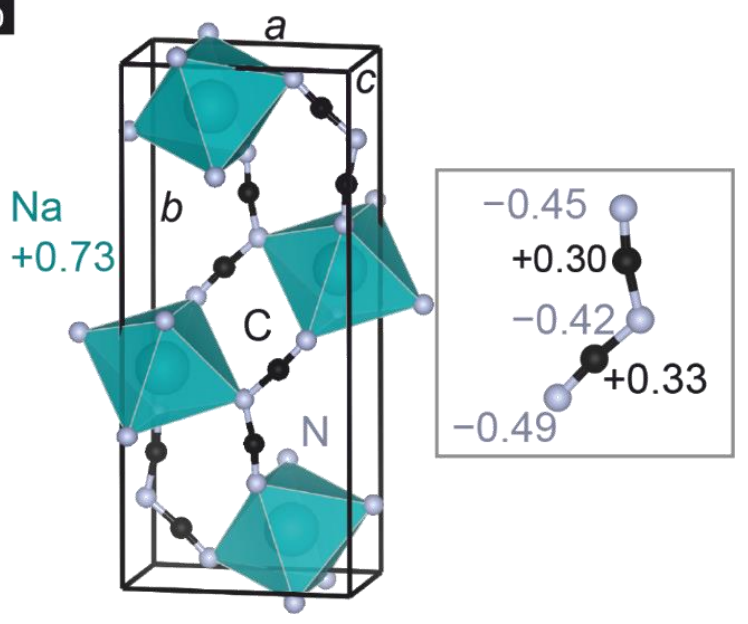

$\mathrm{Na}\left[\mathrm{N}(\mathrm{CN})_{2}\right]$

d

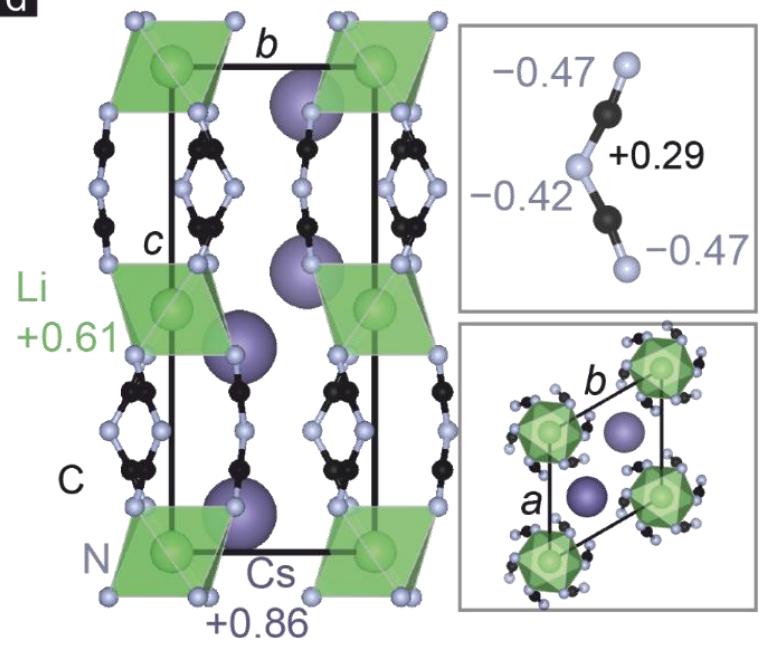

$\mathrm{LiCs}_{2}\left[\mathrm{~N}(\mathrm{CN})_{2}\right]_{3}$

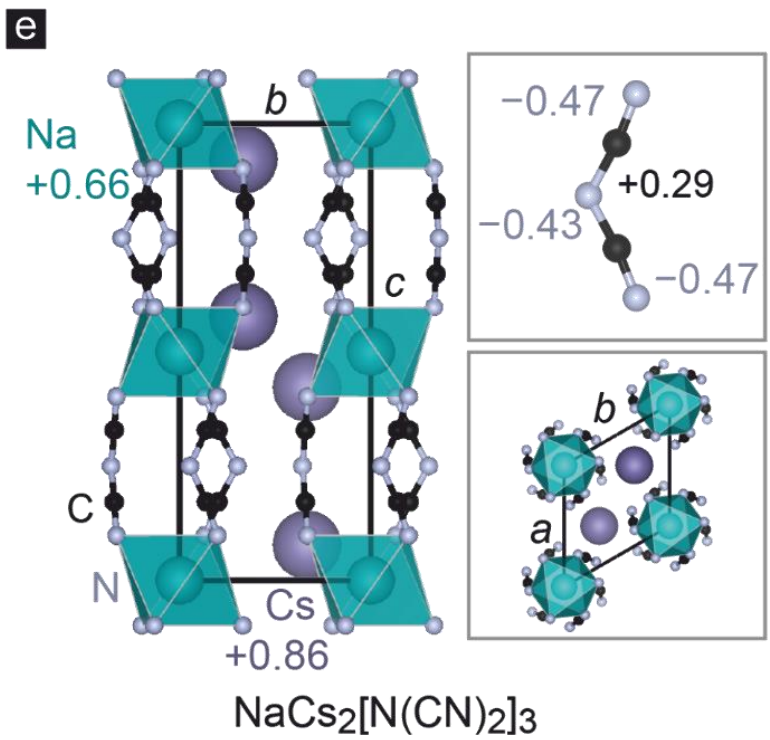

Figure 5. Representations of the crystal structures of a) $\mathrm{Li}\left[\mathrm{N}(\mathrm{CN})_{2}\right]$, b) $\left.\left.\mathrm{Na}\left[\mathrm{N}(\mathrm{CN})_{2}\right], \mathrm{c}\right) \mathrm{Na}_{3}\left[\mathrm{~N}(\mathrm{CN})_{2}\right]_{3}, \mathrm{~d}\right) \mathrm{LiCs}_{2}\left[\mathrm{~N}(\mathrm{CN})_{2}\right]_{3}$ and e) $\mathrm{NaCs}_{2}\left[\mathrm{~N}(\mathrm{CN})_{2}\right]_{3}$. Löwdin charges are included. 
We conclude that by using nanoporous carbonaceous materials one triggers partially reduced charges of the $\mathrm{Li}$ and $\mathrm{Na}$ ions which are likely to improve the materials' intercalation behavior, because smaller charges must result in weaker Coulomb attractions given that the interatomic distances stay the same.

\section{DICYANAMIDE SALTS}

We now turn to next-generation nitrogen-based materials involving complex anions such as carbodiimide, $\mathrm{NCN}^{2-}$, and dicyanamide, $\mathrm{N}(\mathrm{CN})_{2}{ }^{-}$. While carbodiimide salts have already shown their ability to act as anode materials or energy materials in general, ${ }^{86}$ we chose to computationally study various alkali-metal dicyanamides as presumably candidates for such application, say, in Li-ion batteries, not only because of their low molecular weight. An additional advantage over traditional graphite-based materials is that dicyanamide should provide an alternative to intercalate Na since this is impossible in pristine graphite, as alluded to already. ${ }^{8,62,65,66,86-90}$ This is the reason to study some $\mathrm{Li}$ - and Na-containing dicyanamides, namely $\mathrm{Li}\left[\mathrm{N}(\mathrm{CN})_{2}\right](P 2 / c \text {, No. 13; Fig. 5a })^{145}$, $\mathrm{Na}\left[\mathrm{N}(\mathrm{CN})_{2}\right]\left(P 2_{1} / c\right.$, No. 14; Fig. 5b), ${ }^{146} \mathrm{LiCs}_{2}\left[\mathrm{~N}(\mathrm{CN})_{2}\right]_{3}\left(P 6_{3} /\right.$ $m$, No. 176; Fig. $5 d)^{87}$ and $\mathrm{NaCs}_{2}\left[\mathrm{~N}(\mathrm{CN})_{2}\right]_{3}\left(P 6_{3} / m\right.$, No. 176 Fig. 5e), ${ }^{147}$ and compare them with graphite-based materials. In $\mathrm{Na}_{3}\left[\mathrm{~N}(\mathrm{CN})_{2}\right]_{3}\left(P 2_{1} / c\right.$, No. 14; Fig. 5c), ${ }^{146}$ the dicyanamide units are trimerized to begin with and form tricyanomelaminate units. In their electronic ground states, $\mathrm{Li}$ and $\mathrm{Na}$ in $\mathrm{Li}\left[\mathrm{N}(\mathrm{CN})_{2}\right], \mathrm{Na}\left[\mathrm{N}(\mathrm{CN})_{2}\right]$ and $\mathrm{Na}_{3}\left[\mathrm{~N}(\mathrm{CN})_{2}\right]_{3}$ (Fig. 5a-c) arrive at Löwdin charges of about $+0.7 e$, which is somewhat smaller than the cationic Löwdin charge of $+0.8 e$ in $\mathrm{LiC}_{6}$ and $\mathrm{LiC}_{12}$ (Fig. 2). The Li/Na charges further decrease when going to $\mathrm{LiCs}_{2}\left[\mathrm{~N}(\mathrm{CN})_{2}\right]_{3}$, and $\mathrm{NaCs}_{2}\left[\mathrm{~N}(\mathrm{CN})_{2}\right]_{3}$ (Fig. 5d and e) despite the fact that a charge of $+0.9 e$ for $C s$ yields this alkaline metal as being more ionized compared to $\mathrm{Li}$ and $\mathrm{Na}$, fitting well with the electronegativity of these elements ( $c f$. Tab. S9). ${ }^{138,148} \mathrm{Be}-$ cause lower charges on ions correlate with an improved intercalation, ${ }^{134} \mathrm{Cs}$-induced charge reduction of $\mathrm{Li}$ and $\mathrm{Na}$ in case of the dicyanamide salts can be expected to lead to an improved intercalation behavior. To at least theoretically check that working hypothesis, we calculated the corresponding activation energies $E_{A}$ from the total energies of an initial and a transition state of the compounds observed in this work according to the approach by Islam et al. ${ }^{149}$ and others $^{120-131}$ (see also SI). In Fig. S2 of the supplement, the Löwdin charges of the migrating ion ( $\mathrm{Li}$ or $\mathrm{Na}$ ) are plotted against $E_{A}$. The respective migration paths are given in Figs. S3-S5. Quite surprisingly, a convincing correlation between charge and ion-migration activation barrier, often used to describe the intercalation behavior, ${ }^{120-131,149}$ was not clear, though ( $c f$. text in the SI). The intercalation process is presumably too complex to be approximated as a simple, static diffusion process for the observed compounds. Coming back to the dicyanamide compounds, carbon and nitrogen atoms show reasonable Löwdin charges with a range of +0.3 to $+0.4 e$ and -0.4 to $-0.5 e$, respectively, thereby nicely reflecting the expectation from chemical intuition, whereas Bader's method predicts rather unreasonably high charges of approximately $+1.6 e$ and $-1.3 e$, for $\mathrm{C}$ and $\mathrm{N}$ respectively ( $c f$. Tab. S9). Analogous results were obtained in a recent study of divalent $3 d$ transition metal carbodiimides. ${ }^{89}$ The presence of nitrogen leads to a positive charge on the tightly bound carbon inside the complex anion instead of a slightly negative one as it is found in $\mathrm{LiC}_{6}$ and $\mathrm{LiC}_{12}$. In conclusion, the cation charges on $\mathrm{Li}$ (and $\mathrm{Na}$ ) are reduced in the nitrogen containing compounds compared to the graphite-based ones.

Since carbodiimide and dicyanamide compounds are electrochemically active $65,66,86,150$ (but dicyanamide compounds have only been probed for electrolytes ${ }^{150}$ so far, to the best of our knowledge), it is interesting to explore the stability during ion removal by the battery (dis)charging process, at least theoretically, that is, removal of all $\mathrm{Li}$ and $\mathrm{Na}$ atoms from the dicyanamide compounds. The structures of $\mathrm{Na}\left[\mathrm{N}(\mathrm{CN})_{2}\right]$ and $\mathrm{Na}_{3}\left[\mathrm{~N}(\mathrm{CN})_{2}\right]_{3}$ both turn into different crystals of the composition " $\mathrm{C}_{2} \mathrm{~N}_{3}$ " with an odd valence-electron count of $2 \times 4+3 \times$ $5=23$ indicating radical character, and change significantly after repeated electronic structural relaxation including spin polarization (cf. Tab. S10); we will denote them as $\mathrm{v}_{\mathrm{Na}}^{\prime}\left[\mathrm{N}(\mathrm{CN})_{2}\right]$ and $\left(\mathrm{v}_{\mathrm{Na}}^{\prime}\right)_{3}\left[\mathrm{~N}(\mathrm{CN})_{2}\right]_{3}$ in which $\mathrm{v}_{\mathrm{Na}}^{\prime}$ represents the vacant $\mathrm{Na}$ atom position. Likewise, $\mathrm{Li}\left[\mathrm{N}(\mathrm{CN})_{2}\right]$ turns into " $\mathrm{C}_{2} \mathrm{~N}_{3}$ " whereas both $\mathrm{LiCs}_{2}\left[\mathrm{~N}(\mathrm{CN})_{2}\right]_{3}$ and $\mathrm{NaCs}_{2}\left[\mathrm{~N}(\mathrm{CN})_{2}\right]_{3}$ turn into " $\mathrm{Cs}_{2} \mathrm{C}_{6} \mathrm{~N}_{9}$ "; we will denote them as $\mathrm{V}_{\mathrm{Li}}^{\prime}\left[\mathrm{N}(\mathrm{CN})_{2}\right]$, $\mathrm{v}_{\mathrm{Li}}^{\prime} \mathrm{Cs}_{2}\left[\mathrm{~N}(\mathrm{CN})_{2}\right]_{3}$ and $\mathrm{v}_{\mathrm{Na}}^{\prime} \mathrm{Cs}_{2}\left[\mathrm{~N}(\mathrm{CN})_{2}\right]_{3}$ from now on. The three latter compounds ( $c f$. Tab. S10) show the best structural stability (before phononic relaxation) among the five dicyanamide salts tested here. In particular, the Cs ions seem to maintain the overall structure by providing cationic charge. Representative dicyanamide units are shown in Fig. 6.

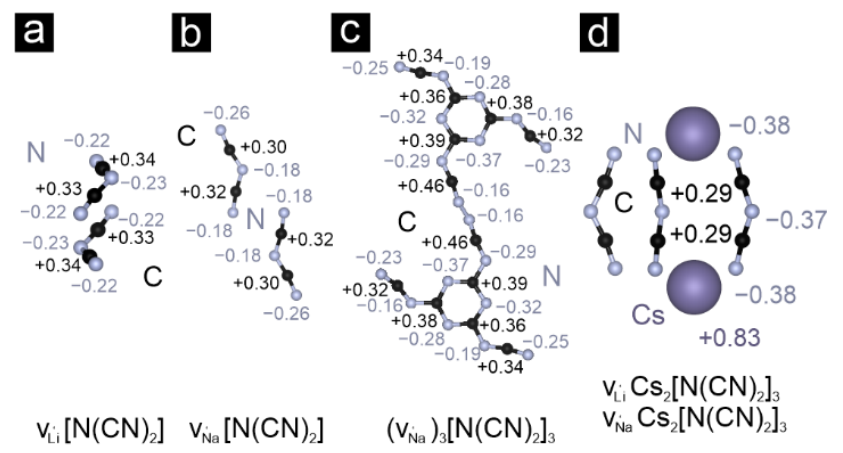

Figure 6. Distribution of Löwdin charges on the dicyanamide units and Cs in the structures from which $\mathrm{Li}$ and $\mathrm{Na}$ have been computationally removed.

In the case of $\left(\mathrm{V}_{\mathrm{Na}}^{\prime}\right)_{3}\left[\mathrm{~N}(\mathrm{CN})_{2}\right]_{3}$, dimerized tricyanomelaminate units are observed (as shown in Fig. 6c and later in Fig. 8c), while such dimerization does not occur in the other cases; as indicated later by phonon calculations, however, there are imaginary modes hidden in the phonon density of states hinting towards structural instability and, hence, likewise dimerization of the dicyanamide units to be anticipated. The charges of the carbon atoms (around $+0.3 e$ ) do not change much in comparison with the ones shown in Fig. 5 , but the charges for nitrogen vary between $-0.2 e$ and $-0.4 e$ in comparison to around $-0.5 e$ in Fig. 5 . Clearly, it is the central $\mathrm{N}$ atom on which the radical leftover electron is to be expected.

Figure S6 in the SI contains the projected densities of states from the spin-polarized structural relaxation calculations. It is apparent from the pDOS plots in Fig. S6 a) and b) that especially the structures of $\mathrm{v}_{\mathrm{Li}}^{\prime}\left[\mathrm{N}(\mathrm{CN})_{2}\right]$ and $\mathrm{v}_{\mathrm{Na}}^{\prime}\left[\mathrm{N}(\mathrm{CN})_{2}\right]$ did not 
reach an energetically favorable ground state yet, visible from a non-existent or too small band gap, indicating metallic or semi-conducting behavior. $\mathrm{v}_{\mathrm{Li}}^{\prime}\left[\mathrm{N}(\mathrm{CN})_{2}\right]$ and $\mathrm{v}_{\mathrm{Na}}^{\prime}\left[\mathrm{N}(\mathrm{CN})_{2}\right]$ result in a non-magnetic structure, with an atomic and total magnetic moment of $0 \mu_{\mathrm{B}}$, which is also a hint towards a nonfavorable structure since a radical character and, therefore, a certain magnetization is expected. $\left(\mathrm{v}_{\mathrm{Na}}^{\prime}\right)_{3}\left[\mathrm{~N}(\mathrm{CN})_{2}\right]_{3}$ exhibits a total magnetic moment of $+2.8 \mu_{\mathrm{B}}$, with most of the magnetization located on the outer nitrogen atoms with a charge of $-0.19 e$ and $-0.25 e$ (cf. Fig. 6c), each one showing an atomic magnetic moment of around $+0.3 \mu_{\mathrm{B}}$. The rather insignificant magnetic moments of the other nitrogen atoms in $\left(\mathrm{v}_{\mathrm{Na}}^{\prime}\right)_{3}\left[\mathrm{~N}(\mathrm{CN})_{2}\right]_{3}$ vary between 0.0 and $+0.08 \mu_{\mathrm{B}}$, and for the carbon atoms, the magnetic moments lie between 0.0 and $-0.06 \mu_{\mathrm{B}} . \mathrm{v}_{\mathrm{Li}}^{\prime} \mathrm{Cs}_{2}\left[\mathrm{~N}(\mathrm{CN})_{2}\right]_{3}$ and $\mathrm{v}_{\mathrm{Na}}^{\prime} \mathrm{Cs}_{2}\left[\mathrm{~N}(\mathrm{CN})_{2}\right]_{3}$ both exhibit a magnetic moment of $+1.4 \mu_{\mathrm{B}}$, in both cases with contributions of $+0.09 \mu_{\mathrm{B}}(\mathrm{N})$ and $-0.02 \mu_{\mathrm{B}}(\mathrm{C})$ but nothing for Cs.

To further check for structural instabilities, in particular for those compounds which did not dimerize during the optimization of the electronic structure, phonon calculation were carried out whose results are displayed in Fig. 7.
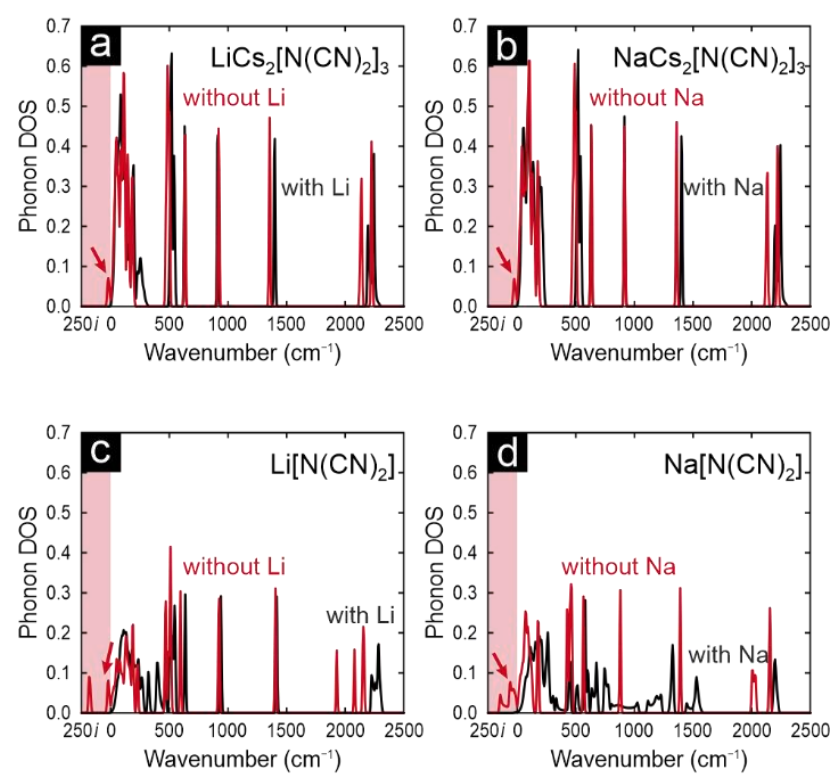

Figure 7. Phonon density of states (DOS) for a) $\left.\mathrm{LiCs}_{2}\left[\mathrm{~N}(\mathrm{CN})_{2}\right]_{3}, \mathrm{~b}\right)$ $\left.\mathrm{NaCs}_{2}\left[\mathrm{~N}(\mathrm{CN})_{2}\right]_{3}, \mathrm{c}\right) \mathrm{Li}\left[\mathrm{N}(\mathrm{CN})_{2}\right]$ and d) $\mathrm{Na}\left[\mathrm{N}(\mathrm{CN})_{2}\right]$ (with and without Li and $\mathrm{Na}$, respectively).

The phonon densities of states evidence that the regular dicyanamide salts (containing $\mathrm{Li}$ and $\mathrm{Na}$ ) are mechanically stable but not so when Li and Na have been removed, at least not given these structures, mirroring the radical problem identified before. As expected, the phonon DOS of $\mathrm{LiCs}_{2}\left[\mathrm{~N}(\mathrm{CN})_{2}\right]_{3}$ and $\mathrm{NaCs}_{2}\left[\mathrm{~N}(\mathrm{CN})_{2}\right]_{3}$ (with and without $\mathrm{Li} / \mathrm{Na}$, respectively) are close to each other to begin with. Devoid of $\mathrm{Li} / \mathrm{Na}$, however, there is a small area in the phonon DOS indicating destabilizing vibrations. The phonon DOS for $\mathrm{Li}\left[\mathrm{N}(\mathrm{CN})_{2}\right]$ and $\mathrm{Na}\left[\mathrm{N}(\mathrm{CN})_{2}\right]$ differ more from the other compounds and the phonon DOS for the structures without $\mathrm{Li} / \mathrm{Na}$ also show a larger phonon DOS in the range of imaginary frequencies. Alternatively expressed, $\mathrm{LiCs}_{2}\left[\mathrm{~N}(\mathrm{CN})_{2}\right]_{3}$ and
$\mathrm{NaCs}_{2}\left[\mathrm{~N}(\mathrm{CN})_{2}\right]_{3}$ may be more robust than $\mathrm{Li}\left[\mathrm{N}(\mathrm{CN})_{2}\right]$ and $\mathrm{Na}\left[\mathrm{N}(\mathrm{CN})_{2}\right]$ upon delithiation and desodiation.

Eventually, Fig. 8 displays the resulting structures after relaxation by applying the eigenvectors of the most imaginary modes to the crystal structures, except for $\left(\mathrm{v}_{\mathrm{Na}}^{\prime}\right)_{3}\left[\mathrm{~N}(\mathrm{CN})_{2}\right]_{3}$ (Fig. 8c), because the structure was already dimerized as mentioned above.

a

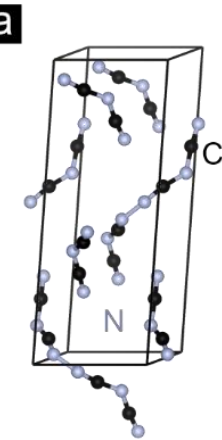

b

C
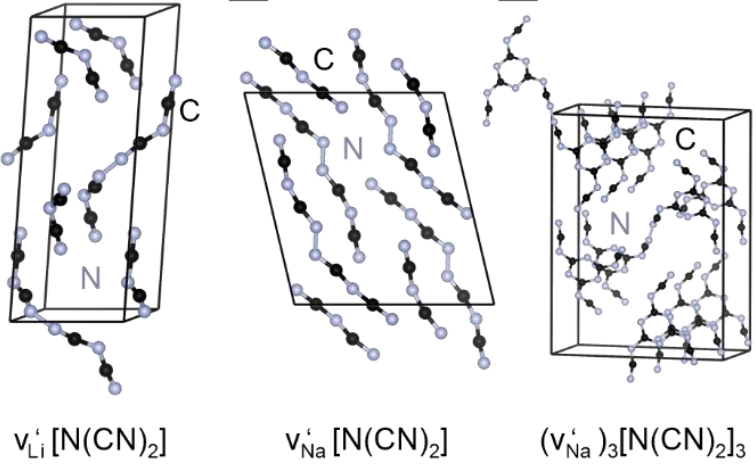

$\mathrm{v}_{\mathrm{Na}}\left[\mathrm{N}(\mathrm{CN})_{2}\right]$

$\left(\mathrm{v}_{\mathrm{Na}}\right)_{3}\left[\mathrm{~N}(\mathrm{CN})_{2}\right]_{3}$

d

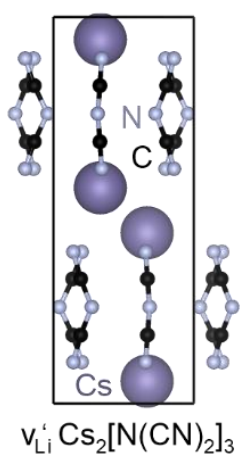

e

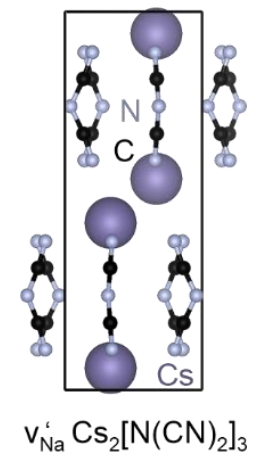

Figure 8. Final structures after phononic relaxation of a) $\mathrm{v}_{\mathrm{Li}}^{\prime}\left[\mathrm{N}(\mathrm{CN})_{2}\right], \quad$ b) $\quad \mathrm{v}_{\mathrm{Na}}^{\prime}\left[\mathrm{N}(\mathrm{CN})_{2}\right], \quad$ c) $\quad\left(\mathrm{v}_{\mathrm{Na}}^{\prime}\right)_{3}\left[\mathrm{~N}(\mathrm{CN})_{2}\right] 3, \quad$ d) $\mathrm{v}_{\mathrm{Li}}^{\prime} \mathrm{Cs}_{2}\left[\mathrm{~N}(\mathrm{CN})_{2}\right]_{3}$ and e) $\mathrm{v}_{\mathrm{Na}}^{\prime} \mathrm{Cs}_{2}\left[\mathrm{~N}(\mathrm{CN})_{2}\right]_{3}$.

The structures reflect that the dicyanamide units in $\mathrm{v}_{\mathrm{Li}}^{\prime}\left[\mathrm{N}(\mathrm{CN})_{2}\right], \mathrm{v}_{\mathrm{Na}}^{\prime}\left[\mathrm{N}(\mathrm{CN})_{2}\right]$ and tricyanomelaminate units in $\left(\mathrm{v}_{\mathrm{Na}}^{\prime}\right)_{3}\left[\mathrm{~N}(\mathrm{CN})_{2}\right]_{3}$ have become dimerized as anticipated from their radical character. The resulting phonon DOS for the dimerized $\mathrm{v}_{\mathrm{Li}}^{\prime}\left[\mathrm{N}(\mathrm{CN})_{2}\right]$ and $\mathrm{v}_{\mathrm{Na}}^{\prime}\left[\mathrm{N}(\mathrm{CN})_{2}\right]$ structures is shown in Fig. S7 in the SI. The structures of $\mathrm{v}_{\mathrm{Li}}^{\prime} \mathrm{Cs}_{2}\left[\mathrm{~N}(\mathrm{CN})_{2}\right]_{3}$ and $\mathrm{v}_{\mathrm{Na}}^{\prime} \mathrm{Cs}_{2}\left[\mathrm{~N}(\mathrm{CN})_{2}\right]_{3}$, however, did not change much, the only significant difference being a small stretch (12\%) of the unit cell along the $c$ lattice parameter compared to the original structure ( $c f$. Fig. $5 \mathrm{~d}$ and e). One may assume that the ionic character of the Cs compounds and their inherent Madelung field leads to some extra stabilization, thereby also compensating the radical character.

Having a look at the projected electronic DOS of the final structures (Fig. 9) reveals that, in case of $\mathrm{v}_{\mathrm{Li}}^{\prime}\left[\mathrm{N}(\mathrm{CN})_{2}\right]$ and $\mathrm{v}_{\mathrm{Na}}^{\prime}\left[\mathrm{N}(\mathrm{CN})_{2}\right]$, the unfavorable electronic state has disappeared. The resulting dimerized compounds now show a wider band gap (Fig. $9 \mathrm{a}, \mathrm{b}$ ) and no magnetization whatsoever. The projected DOS for $\mathrm{v}_{\mathrm{Li}}^{\prime} \mathrm{Cs}_{2}\left[\mathrm{~N}(\mathrm{CN})_{2}\right]_{3}$ and $\mathrm{v}_{\mathrm{Na}}^{\prime} \mathrm{Cs}_{2}\left[\mathrm{~N}(\mathrm{CN})_{2}\right]_{3}$ do not vary much from the one before structural relaxation (Fig. 9 d, e vs. Fig S6 d, e) due to a lack of structural change. 

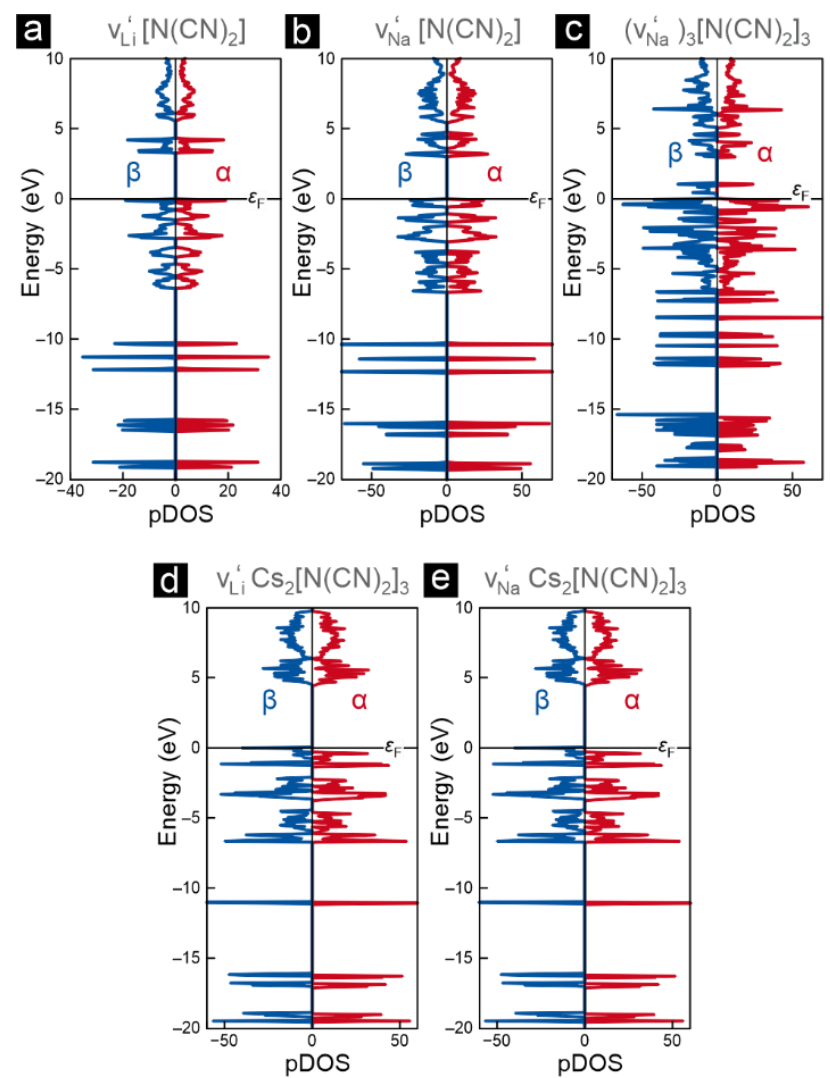

Figure 9. Projected density of states (pDOS) plots for the dicyanamide-containing compounds without Li and $\mathrm{Na}$ a, b, d, and e show the DOS after phononic relaxation. c shows the same pDOS as Fig. S6 c.

At this point, a closer analysis of the chemical bonding in the various dicyanamides before and after $\mathrm{Li} / \mathrm{Na}$ removal seems appropriate, carried out from projected crystal orbital Hamilton populations ( $\mathrm{pCOHP}$ ) and visualized as regards the terminal $\mathrm{C} \equiv \mathrm{N}$ triple bonds in Fig. 10.

The levels for the $\mathrm{Li} / \mathrm{Na}$-containing salts (in red) are discrete, molecular-like, in particular at energies below $15 \mathrm{eV}$ (strongest contribution) and below $-10 \mathrm{eV}$, but there is also a broader, solid-state-like part with stonger orbital interaction just below the Fermi level. After Li/Na have been removed, there are structural changes in $\mathrm{v}_{\mathrm{Li}}^{\prime}\left[\mathrm{N}(\mathrm{CN})_{2}\right]$, $\mathrm{v}_{\mathrm{Na}}^{\prime}\left[\mathrm{N}(\mathrm{CN})_{2}\right]$ and $\left(\mathrm{v}_{\mathrm{Na}}^{\prime}\right)_{3}\left[\mathrm{~N}(\mathrm{CN})_{2}\right]_{3}$, in particular as regards the formation of a new N-N bond, and the new levels associated with the chemical bonding (in blue) shift up in energy and the bond weakens as a function of the wider interatomic distance in the terminal $\mathrm{C} \equiv \mathrm{N}$ triple bonds. The ionic contribution of $\mathrm{Li} / \mathrm{Na}$ also vanishes upon their removal (energy levels just below the Fermi level). Note, however, that $\mathrm{v}_{\mathrm{Li}}^{\prime} \mathrm{Cs}_{2}\left[\mathrm{~N}(\mathrm{CN})_{2}\right]_{3}$ and $\mathrm{v}_{\mathrm{Na}}^{\prime} \mathrm{Cs}_{2}\left[\mathrm{~N}(\mathrm{CN})_{2}\right]_{3}$ do not vary much from their original structure since the dicyanamide units will not dimerize, so the projected COHP plot without Li/Na does not significantly differ in these two cases from those with Li/Na ( $c f$. Fig. 10 d, e).

For ease of comparison, we offer a closer and simplified look at the transformation of the dicyanamide/tricyanomelaminate monomer to the dimerized unit in Fig. 11, including the energy integrals of the projected COHP value for the individual $\mathrm{C}-\mathrm{N}$ and $\mathrm{N}-\mathrm{N}$ bonds.
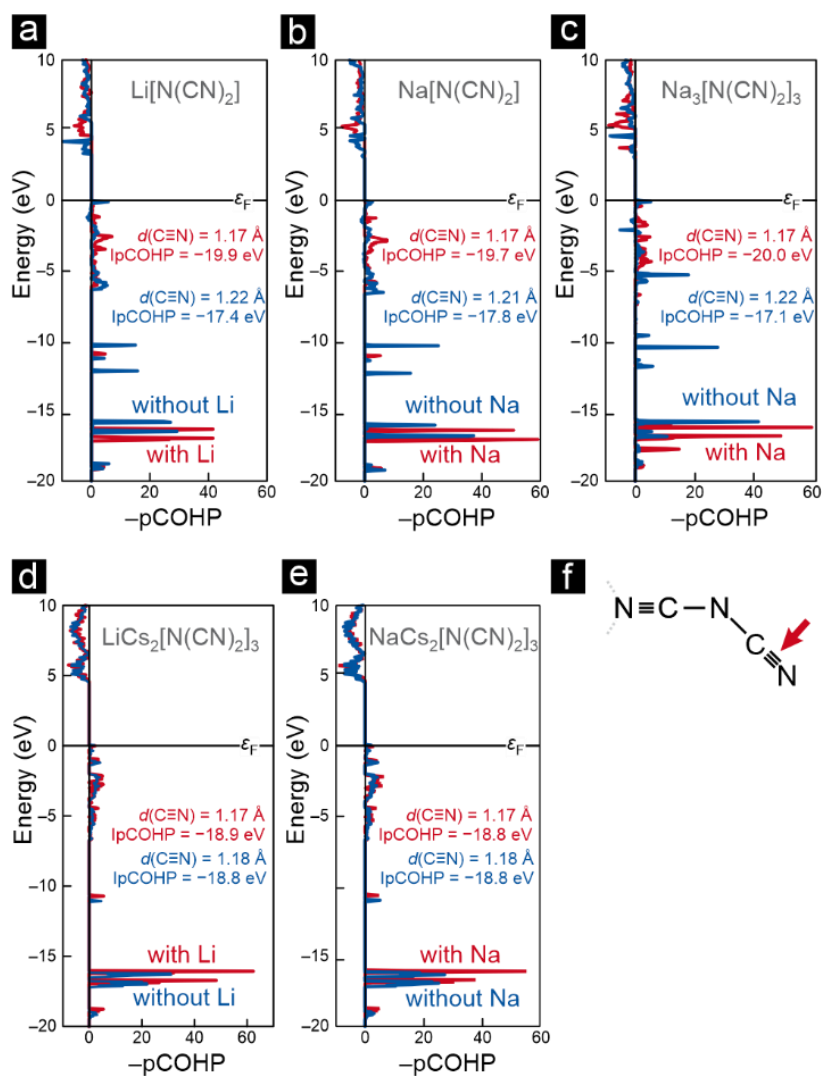

Figure 10. Projected COHP plots for the terminal $\mathrm{C} \equiv \mathrm{N}$ triple bond f) in the dicyanamide/tricyanomelaminate salts with $\mathrm{Li}$ and $\mathrm{Na}$ compared to the ones without $\mathrm{Li}$ and $\mathrm{Na}$.

All dicyanamide/tricyanomelaminate units in $\mathrm{Li}\left[\mathrm{N}(\mathrm{CN})_{2}\right]$, $\mathrm{Na}\left[\mathrm{N}(\mathrm{CN})_{2}\right], \quad \mathrm{Na}_{3}\left[\mathrm{~N}(\mathrm{CN})_{2}\right]_{3}, \quad \mathrm{LiCs}_{2}\left[\mathrm{~N}(\mathrm{CN})_{2}\right]_{3} \quad$ and $\mathrm{NaCs}_{2}\left[\mathrm{~N}(\mathrm{CN})_{2}\right]_{3}$ are chemically very similar to each other in terms of the $\mathrm{C} \equiv \mathrm{N}$ triple bonds ( $1.17 \AA$, IpCOHP about $-20 \mathrm{eV}$ ) and the $\mathrm{C}-\mathrm{N}$ single bonds (1.29 $\AA$, IpCOHP about $-14 \mathrm{eV})$, and that does not change significantly for $\mathrm{v}_{\mathrm{Li}}^{\prime} \mathrm{Cs}_{2}\left[\mathrm{~N}(\mathrm{CN})_{2}\right]_{3}$ and $\mathrm{v}_{\mathrm{Na}}^{\prime} \mathrm{Cs}_{2}\left[\mathrm{~N}(\mathrm{CN})_{2}\right]_{3}$ ( $c f$. Fig. $\left.11 \mathrm{~d}, \mathrm{e}\right)$; as indicated before, the Madelung field of the Cs-containing salts stabilizes those in terms of structure and energy. The energetic order of magnitude of the IpCOHP for the $\mathrm{C}-\mathrm{N}$ bonds agree with values that have been reported before. ${ }^{151}$ In the structures dimerizing upon $\mathrm{Li} / \mathrm{Na}$ removal, however, one $\mathrm{C} \equiv \mathrm{N}$ triple and one $\mathrm{C}-\mathrm{N}$ single bond turn into two $\mathrm{C}=\mathrm{N}$ double bonds $(1.23 \AA)$ due to the formation of a new $\mathrm{N}-\mathrm{N}$ bond ( $c f$. Fig. $11 \mathrm{a}, \mathrm{b}, \mathrm{c}$ ). The double bond corresponds to those in metal carbodiimide compounds, about $1.22 \AA$, $152-156$ whereas other $\mathrm{C}=\mathrm{N}$ bond types like in imines arrive at around $1.3 \AA{ }^{157}$ It is noteworthy mentioning that DFT-based energetic evaluation of bonds with differing bond orders can be misleading due to a DFT delocalization error, ${ }^{158}$ falsely predicting the relative stabilities of mercury carbodiimide and cyanamide, $\mathrm{HgNCN}$; experimentally, the cyanamide phase with a $\mathrm{C} \equiv \mathrm{N}$ triple and a $\mathrm{C}-\mathrm{N}$ single bond is the more stable polymorph. ${ }^{152}$ Hence, we used tabulated bonddissociation energies ${ }^{159} D_{0}$ to estimate the energetic situation upon dimerization. Based on $D_{0}$ for $\mathrm{HC} \equiv \mathrm{H}, \mathrm{H}_{2} \mathrm{C}=\mathrm{NH}, \mathrm{H}_{3} \mathrm{C}-\mathrm{NH}_{2}$ and $\mathrm{H}_{2} \mathrm{~N}-\mathrm{NH}_{2}$ ( $c f$. Tab. S11), the energy gain for cleaving a $\mathrm{C} \equiv \mathrm{N}$ triple and a $\mathrm{C}-\mathrm{N}$ single bond as well as forming two $\mathrm{C}=\mathrm{N}$ double and a new N-N single bond lies around $-263 \mathrm{~kJ} \mathrm{~mol}^{-1}$, clearly indicating that dimerization is energetically favored. 


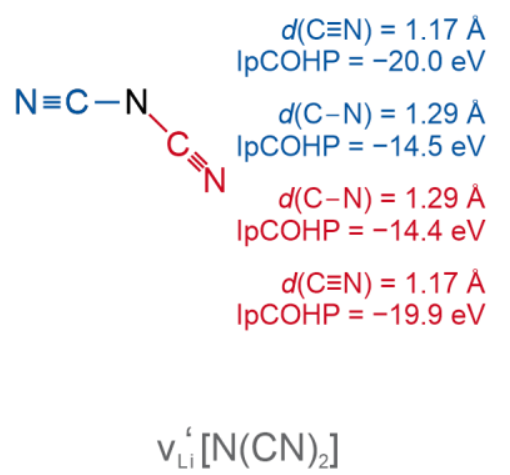

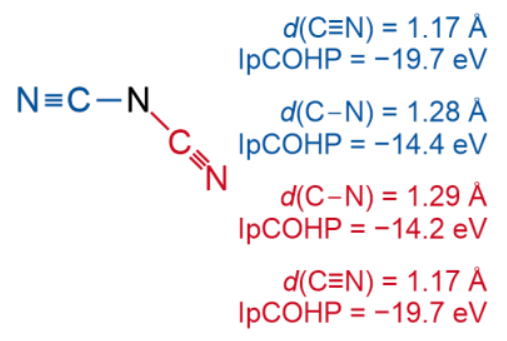

$\mathrm{V}_{\mathrm{Na}}^{\mathrm{a}}\left[\mathrm{N}(\mathrm{CN})_{2}\right]$

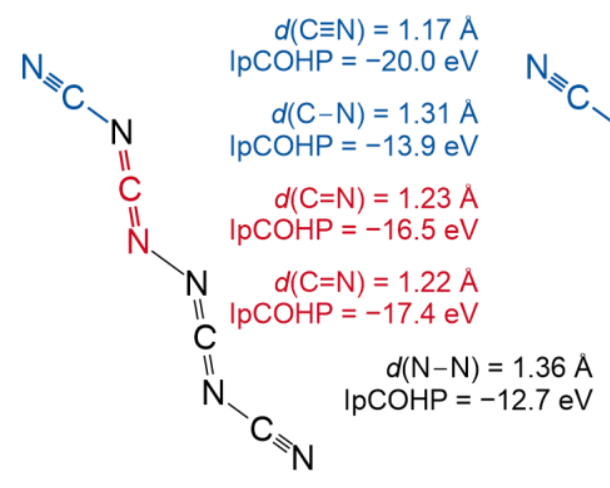

II

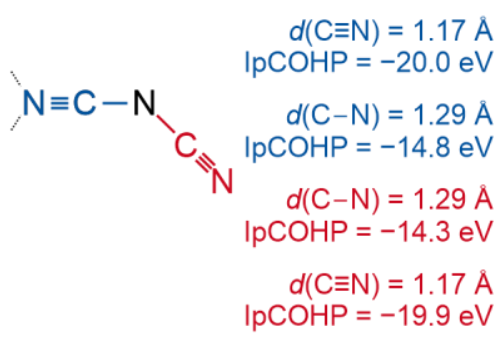

$\left(\mathrm{v}_{\mathrm{Na}}^{\prime}\right)_{3}\left[\mathrm{~N}(\mathrm{CN})_{2}\right]_{3}$

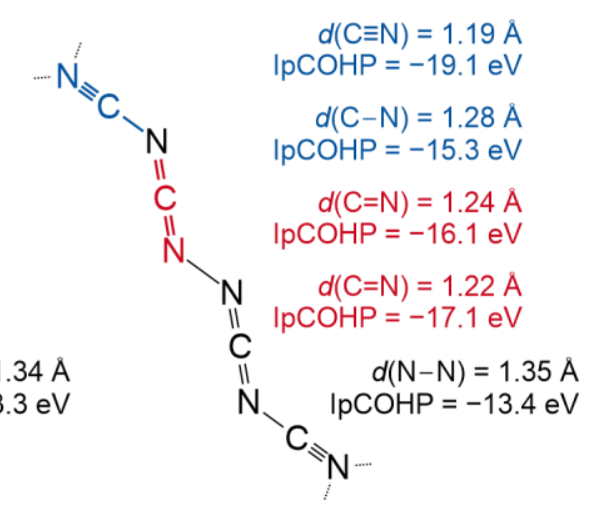

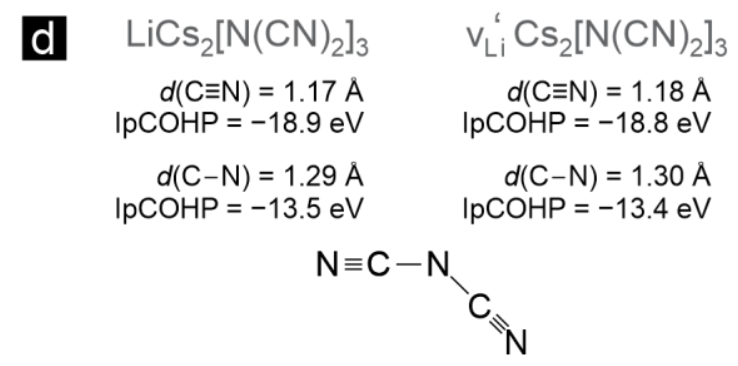

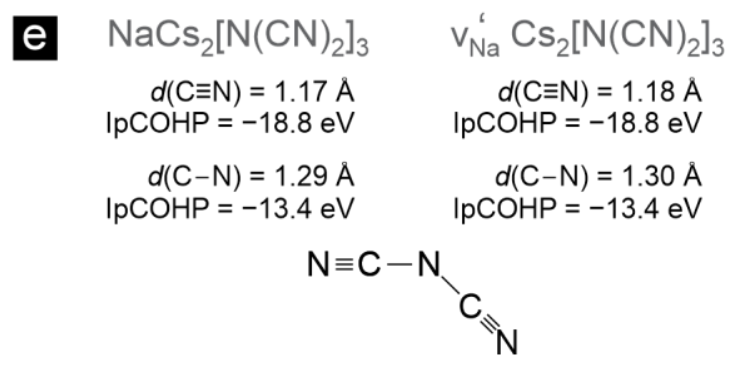

Figure 11. Energy integrals of the projected COHP values (IpCOHP) for the $\mathrm{C} \equiv \mathrm{N}$ triple, $\mathrm{C}=\mathrm{N}$ double and $\mathrm{C}-\mathrm{N}$ as well as $\mathrm{N}-\mathrm{N}$ single bonds in the dicyanamide/tricyanomelaminate monomer and dimer units.

In general, the salts of the dicyanamides tested here seem to be robust against the removal of Li or Na cations due to dimerization of the $\left[\mathrm{N}(\mathrm{CN})_{2}\right]$ radicals, with the fortunate exception of the Cs-containing compounds which are stable even without dimerization. Hence, $\mathrm{LiCs}_{2}\left[\mathrm{~N}(\mathrm{CN})_{2}\right]_{3}$ and $\mathrm{NaCs}_{2}\left[\mathrm{~N}(\mathrm{CN})_{2}\right]_{3}$ are most suitable among the dicyanamide salts tested here to act as electrode material. The occurrence of stable nitrogen-centered (and also phosphor-centered) radicals is at least not uncommon and was also reported in the literature for other compounds. ${ }^{160-162}$

To ultimately test if the dicyanamide and tricyanomelaminate compounds have cathodic or anodic character, the reaction equations (1-5) in scheme 1 can be formulated for the reactions of the dicyanamide and tricyanomelaminate salts with commercial cathode materials $\mathrm{LiCoO}_{2}$ and $\mathrm{NaFePO}_{4}$ within a battery. The respective reaction enthalpy $\Delta H_{\mathrm{r}}$ is estimated from total energies ${ }^{83,163}$ of the involved compounds. The resulting electrochemical potential $\Delta E$ is approximated via the battery equation $\Delta H \approx \Delta G=-n F \Delta E$.

Since the reaction enthalpies turned out to be positive for all five compounds, it seems that these materials rather have a cathodic character than an anodic one. Admittedly, the activation energy for ion migration - an important measure for $\mathrm{Li}$ and $\mathrm{Na}$ ion mobility in battery materials - of $\mathrm{LiCs}_{2}\left[\mathrm{~N}(\mathrm{CN})_{2}\right]_{3}$, $\mathrm{NaCs}_{2}\left[\mathrm{~N}(\mathrm{CN})_{2}\right]_{3}, \mathrm{Na}_{3}\left[\mathrm{~N}(\mathrm{CN})_{2}\right]_{3}$ and $\mathrm{Na}\left[\mathrm{N}(\mathrm{CN})_{2}\right]$ lie around $1 \mathrm{eV}$ and that for $\mathrm{Li}\left[\mathrm{N}(\mathrm{CN})_{2}\right]$ around $0.5 \mathrm{eV}$, whereas commercially available materials like $\mathrm{LiCoO}_{2}$ excel with about $0.3 \mathrm{eV}$ ( $c f$. Fig. S2), but as discussed above, this finding can also be due to a too simple diffusion model. 


$$
\begin{aligned}
& 2 \mathrm{Li}\left[\mathrm{N}(\mathrm{CN})_{2}\right]_{(\mathrm{s})}+2 \mathrm{CoO}_{2(\mathrm{ss})} \rightarrow\left(\left[\mathrm{N}(\mathrm{CN})_{2}\right]\right)_{2(\mathrm{~s})}+2 \mathrm{LiCoO}_{2(\mathrm{~s})} \\
& 2 \mathrm{Na}\left[\mathrm{N}(\mathrm{CN})_{2}\right]_{(\mathrm{s})}+2 \mathrm{FePO}_{4(\mathrm{~s})} \rightarrow\left(\left[\mathrm{N}(\mathrm{CN})_{2}\right]_{2(\mathrm{~s})}+2 \mathrm{NaFePO}_{4(\mathrm{~s})},\right. \\
& 2 \mathrm{Na}_{3}\left[\mathrm{~N}(\mathrm{CN})_{2}\right]_{3(\mathrm{~s})}+6 \mathrm{FePO}_{4(\mathrm{~s})} \rightarrow\left(\left[\mathrm{N}(\mathrm{CN})_{2}\right]_{3}\right)_{2(\mathrm{~s})}+6 \mathrm{NaFePO}_{4(\mathrm{~s})}, \\
& \mathrm{LiCs}_{2}\left[\mathrm{~N}(\mathrm{CN})_{2}\right]_{3(\mathrm{~s})}+\mathrm{CoO}_{2(\mathrm{~s})} \rightarrow \mathrm{Cs}_{2}\left[\mathrm{~N}(\mathrm{CN})_{2}\right]_{3(\mathrm{~s})}+\mathrm{LiCoO}_{2(\mathrm{~s})}, \\
& \mathrm{NaCs}_{2}\left[\mathrm{~N}(\mathrm{CN})_{2}\right]_{3(\mathrm{~s})}+\mathrm{FePO}_{4(\mathrm{~s})} \rightarrow \mathrm{Cs}_{2}\left[\mathrm{~N}(\mathrm{CN})_{2}\right]_{3(\mathrm{~s})}+\mathrm{NaFePO}_{4(\mathrm{~s})},
\end{aligned}
$$

$$
\begin{aligned}
& \Delta H_{r}=30.5 \mathrm{~kJ} \mathrm{~mol}^{-1} \hat{=}-0.3 \mathrm{~V} \\
& \Delta H_{r}=92.3 \mathrm{~kJ} \mathrm{~mol}^{-1} \hat{=}-0.9 \mathrm{~V} \\
& \Delta H_{r}=100.4 \mathrm{~kJ} \mathrm{~mol}^{-1} \hat{=}-1.0 \mathrm{~V} \\
& \Delta H_{r}=70.6 \mathrm{~kJ} \mathrm{~mol}^{-1} \hat{=}-0.7 \mathrm{~V} \\
& \Delta H_{r}=155.2 \mathrm{~kJ} \mathrm{~mol}^{-1} \hat{=}-1.6 \mathrm{~V}
\end{aligned}
$$

Scheme 1. Reaction schemes for dicyanamide salts with cathode materials $\mathrm{LiCoO}_{2}$ and $\mathrm{LiFePO}_{4}$.

Metal dicyanamides and related compounds are stable in acid and basic media, ${ }^{90,164}$ and are generally known for a high thermal and chemical stability. 150, 153, 154, 165-170 Thermally induced polymerization is known for some compounds to happen after being heated above $500{ }^{\circ} \mathrm{C} \cdot 1^{170-172}$ In case of alkali metal dicyanamide salts $\left(\mathrm{M}\left[\mathrm{N}(\mathrm{CN})_{2}\right], M=\mathrm{Na}, \mathrm{K}, \mathrm{Rb}\right)$, thermally induced trimerization ${ }^{146,147,165,173}$ of the dicyanamide units to cyclic tricyanomelaminate anions is known to occur above $300{ }^{\circ} \mathrm{C}$, whereas polymerization is known for $\mathrm{Li}\left[\mathrm{N}(\mathrm{CN})_{2}\right]$ at around $300{ }^{\circ} \mathrm{C},{ }^{174}$ indicating a high thermal stability of these compounds. Additionally, it is possible to monomerize $\mathrm{Na}_{3}\left[\mathrm{~N}(\mathrm{CN})_{2}\right]_{3}$ via ion exchange, so that $\mathrm{NaCs}_{2}\left[\mathrm{~N}(\mathrm{CN})_{2}\right]_{3}$ is obtained, containing dicyanamide units, not tricyanomelaminate units. ${ }^{147}$ This means that the trimerization process is reversible in general and therefore any (partial) oligomerization/polymerization during the discharge process in a battery can be reversible, as well. With a relative density to $\mathrm{LiCoO}_{2}$ with $\rho_{\text {calc }}=5.1 \mathrm{~g} \mathrm{~cm}^{-3}\left(\mathrm{LiC}_{6}\right.$ and $\mathrm{LiC}_{12}, \rho_{\text {calc }}=$ $\left.2.2 \mathrm{~g} \mathrm{~cm}^{-3}\right)^{64,139,175}$ of $0.3(0.7), 0.3(0.8)$ and $0.4(0.9)$ for $\mathrm{Li}\left[\mathrm{N}(\mathrm{CN})_{2}\right], \mathrm{Na}\left[\mathrm{N}(\mathrm{CN})_{2}\right]$ and $\mathrm{Na}_{3}\left[\mathrm{~N}(\mathrm{CN})_{2}\right]_{3}$, respectively and 0.5 (1.2) for $\mathrm{LiCs}_{2}\left[\mathrm{~N}(\mathrm{CN})_{2}\right]_{3}$ and $\mathrm{NaCs}_{2}\left[\mathrm{~N}(\mathrm{CN})_{2}\right]_{3}$, these compounds can also compete in terms of bulk properties with commercially used electrode materials.

Based on the intriguing properties of dicyanamide salts reported in the literature and the findings of the current work, we encourage experimentalists to evaluate dicyanamide salts for the application as electrode materials in battery technology.

\section{CONCLUSIONS}

In conclusion, Löwdin's population analysis has been utilized to investigate cathode and anode materials for $\mathrm{Li}$ and $\mathrm{Na}$ ion batteries. Generally speaking, such wavefunction-based analysis is able to yield chemically reasonable charges. In case of the cathode materials $\mathrm{LiCoO}_{2}, \mathrm{LiFePO}_{4}$ and $\mathrm{NaFePO}_{4}$, the magnetic order or the use of a $U$ parameter did not have a major influence of the compounds' charges and the trend of the charges among the three compounds agreed with the experimentally known, good intercalation behavior of $\mathrm{LiCoO}_{2}{ }^{1}, 7,55$, ${ }^{56} \mathrm{New}$ insight towards the improvement of the intercalation behavior in electrode materials was given by switching from graphite based materials to dicyanamide salts and nanoporous compounds, due to a decrease in cation charge. Moreover, the structure of $\mathrm{LiC}_{6}$ is stabilized through a significant covalent contribution from the $\mathrm{Li}-\mathrm{C}$ bond, despite the dominant ionic bonding character. On the other side, nanoporous materials such as $\mathrm{Li}_{12} \mathrm{C}_{194}, \mathrm{Li}_{28} \mathrm{C}_{196}, \mathrm{Li}_{32} \mathrm{C}_{196}$ and $\mathrm{Na}_{14} \mathrm{C}_{206}$ display various cationic Löwdin charges, and these charges are likewise reduced for compounds such as $\mathrm{Li}\left[\mathrm{N}(\mathrm{CN})_{2}\right], \mathrm{Na}\left[\mathrm{N}(\mathrm{CN})_{2}\right]$ and $\mathrm{Na}_{3}\left[\mathrm{~N}(\mathrm{CN})_{2}\right]_{3}$ which are clearly smaller than in $\mathrm{LiC}_{6}$ and $\mathrm{LiC}_{12}$, the strongest reduction being found for the Cs-containing phases like $\mathrm{LiCs}_{2}\left[\mathrm{~N}(\mathrm{CN})_{2}\right]_{3}$, and $\mathrm{NaCs}_{2}\left[\mathrm{~N}(\mathrm{CN})_{2}\right]_{3}$. Upon delithiation and desodiation, dicyanamide salts behave differently as a function of their complexity: $\operatorname{LiCs}_{2}\left[\mathrm{~N}(\mathrm{CN})_{2}\right]_{3}$ and $\mathrm{NaCs}_{2}\left[\mathrm{~N}(\mathrm{CN})_{2}\right]_{3}$ devoid of Li/Na stay structurally almost the same, in particular as regards the dicyanamide units; remaining phononic instabilities are negligible. In the case of the binary dicyanamides, energetically beneficial dimerization and the formation of a new $\mathrm{N}-\mathrm{N}$ single bond appears, in addition to changing neighboring $\mathrm{C}-\mathrm{N}$ single/triple bonds to double bond character. With low densities for all five dicyanamide compounds and electrochemical activity, in addition to the high thermal stability, these materials can theoretically compete with commercially available electrode materials. We hope to have stimulated independent experimental results as regards the suitability of dicyanamide salts as electrode materials in $\mathrm{Li}$ and $\mathrm{Na}$ batteries.

\section{ASSOCIATED CONTENT}

\section{Supporting Information.}

Table S1. Mulliken and Löwdin charges for different magnetization models for $\mathrm{LiCoO}_{2}$.

Table S2. As before but for $\mathrm{LiFePO}_{4}$.

Table S3. As before but for $\mathrm{NaFePO}_{4}$.

Table S4. Lattice parameters and k-point set for the compounds presented in this work.

Table S5. Supercell size, defect structure and activation energies of the Li and Na-compounds presented in this work.

Table S6. Mulliken and Löwdin charges of cathode materials $\mathrm{LiCoO}_{2}, \mathrm{LiFeO}_{4}$ and $\mathrm{NaFePO}_{4}$ in comparison with Bader charges.

Table S7. Mulliken and Löwdin charges of several Li, Na and K containing graphite-like anode materials in comparison with Bader charges.

Table S8. Detailed comparison of Mulliken, Löwdin and Bader charges for $\mathrm{LiC}_{6}, \mathrm{LiC}_{12}$ and model structures $\mathrm{NaC}_{6}$ and $\mathrm{KC}_{6}$.

Table S9. Mulliken and Löwdin charges of $\operatorname{Li}\left[\mathrm{N}(\mathrm{CN})_{2}\right]$, $\mathrm{Na}\left[\mathrm{N}(\mathrm{CN})_{2}\right], \mathrm{Na}_{3}\left[\mathrm{~N}(\mathrm{CN})_{2}\right]_{3}, \mathrm{LiCs}_{2}\left[\mathrm{~N}(\mathrm{CN})_{2}\right]_{3}$ and $\mathrm{NaCs}_{2}\left[\mathrm{~N}(\mathrm{CN})_{2}\right]_{3}$ in comparison with Bader charges. 
Table S10. Lattice parameters of the relaxed structures (before phonon calculations) of the dicyanamide-containing compounds without $\mathrm{Li}$ and $\mathrm{Na}$ and the change of the lattice parameter with respect to the relaxed structures containing $\mathrm{Li}$ and $\mathrm{Na}$.

Table S11. Bond dissociation energies $D_{0}$ for $\mathrm{HC} \equiv \mathrm{H}, \mathrm{H}_{2} \mathrm{C}=\mathrm{NH}$, $\mathrm{H}_{3} \mathrm{C}-\mathrm{NH}_{2}$ and $\mathrm{H}_{2} \mathrm{~N}-\mathrm{NH}_{2}$ given for the homolytic reaction of $\mathrm{A}-\mathrm{B}$ $\rightarrow \mathrm{A}^{*}+\mathrm{B}^{*}$.

Figure S1. Comparison of projected density of states (pDOS) without and with $U$ parameter of a) $\mathrm{LiCoO}_{2}$, b) $\mathrm{LiFePO}_{4}$ and c) $\mathrm{NaFePO}_{4}$ in the antiferromagnetic states.

Figure S2. Löwdin charge of the migrating ion vs. activation en$\operatorname{ergy} \boldsymbol{E}_{\boldsymbol{A}}$.

Figure S3. Migration paths of the ions in the cathode materials. a) $\mathrm{LiCoO}_{2}: \mathrm{Li}^{+}$ions move from octahedral site to octrahedral site via passing a tetrahedral site along the $a$ axis. ${ }^{120,}{ }^{123}$ b) $\mathrm{LiFePO}_{4}: \mathrm{Li}^{+}$ions move between octahedral and interstitial $\begin{array}{llll}\text { sites along the } b \text { axis. }{ }^{125,} 126, & 129\end{array}$ c) $\mathrm{NaFePO}_{4}: \mathrm{Na}^{+}$ions also move along the $b$ axis. ${ }^{122,127}$ d) $\mathrm{LiC}_{6}$ and $\mathrm{LiC}_{12}: \mathrm{Li}^{+}$ions show the smallest migration activation energy barrier for the shown path. ${ }^{124,128}$

Figure S4. Migration paths of a) $\mathrm{Li}^{+}$in $\mathrm{Li}\left[\mathrm{N}(\mathrm{CN})_{2}\right]$, b) $\mathrm{Na}^{+}$in $\mathrm{Na}\left[\mathrm{N}(\mathrm{CN})_{2}\right]$, c) $\mathrm{Na}^{+}$in $\left.\mathrm{Na}_{3}\left[\mathrm{~N}(\mathrm{CN})_{2}\right]_{3}, \mathrm{~d}\right) \mathrm{Li}^{+}$in $\mathrm{LiCs}_{2}\left[\mathrm{~N}(\mathrm{CN})_{2}\right]_{3}$, and e) $\mathrm{Na}^{+}$in $\mathrm{NaCs}_{2}\left[\mathrm{~N}(\mathrm{CN})_{2}\right]_{3}$.

Figure S5. Migration paths of a) $\mathrm{Na}^{+}$through the carbon backbone and b) $\mathrm{Na}^{+}$through a pore in $\mathrm{Na}_{14} \mathrm{C}_{206}$, as well as c) $\mathrm{Li}^{+}$ along a graphen-like layer in $\mathrm{Li}_{12} \mathrm{C}_{194}$ and d) $\mathrm{Li}^{+}$along a graphenlike layer in $\mathrm{Li}_{28} \mathrm{C}_{196}$.

Figure S6. Projected density of states (pDOS) plots for the dicyanamide-containing compounds without $\mathrm{Li}$ and $\mathrm{Na}$ after structural relaxation and before phononic relaxation.

Figure S7. Phonon density of states for $\mathrm{v}_{\mathrm{Li}}^{\prime}\left[\mathrm{N}(\mathrm{CN})_{2}\right]$ and $\mathrm{v}_{\mathrm{Na}}^{\prime}\left[\mathrm{N}(\mathrm{CN})_{2}\right]$.

This material is available free of charge via the Internet at http://pubs.acs.org.

\section{AUTHOR INFORMATION}

\section{Corresponding Author}

Richard Dronskowski -Chair of Solid-State and Quantum Chemistry, Institute of Inorganic Chemistry, RWTH Aachen University, D-52056 Aachen, Germany; Hoffmann Institute of Advanced Materials, Shenzhen Polytechnic, Shenzhen, China; orcid.org/0000-0002-1925-9624;

Email: drons@HAL9000.ac.rwth-aachen.de

\section{Authors}

Christina Ertural -Chair of Solid-State and Quantum Chemistry, Institute of Inorganic Chemistry, RWTH Aachen University, D-52056 Aachen, Germany

Ralf P. Stoffel -Chair of Solid-State and Quantum Chemistry, Institute of Inorganic Chemistry, RWTH Aachen University, D-52056 Aachen, Germany
Peter C. Müller - Chair of Solid-State and Quantum Chemistry, Institute of Inorganic Chemistry, RWTH Aachen University, D-52056 Aachen, Germany

C. Alexander Vogt -Chair of Solid-State and Quantum Chemistry, Institute of Inorganic Chemistry, RWTH Aachen University, D-52056 Aachen, Germany

Notes

The authors declare no competing financial interest.

\section{ACKNOWLEDGMENT}

The authors wish to thank the IT Center of RWTH Aachen University for providing the computational time as well as the resources under project jara0033. We also want to thank Prof. Dr. Volker L. Deringer for providing excellent ideas for the basic concept of this work, Dr. Markus Mann for suggesting to investigate dicyanamide and related salts and Jan Hempelmann for proofreading.

This publication is dedicated to the memory of our colleague, dear friend and software developer Dr. Bernhard Eck, inventor of the beautiful tool wxDragon, who passed away last year. Without him, this and other works of the past would have been much more difficult to accomplish.

\section{REFERENCES}

1. Islam, M. S.; Fisher, C. A. J., Lithium and sodium battery cathode materials: computational insights into voltage, diffusion and nanostructural properties. Chem. Soc. Rev. 2014, 43, 185204.

2. Whittingham, M. S., Materials challenges facing electrical energy storage. MRS Bull. 2008, 33 (4), 411-419.

3. Liu, J.; Zhang, J.-G.; Yang, Z.; Lemmon, J. P.; Imhoff, C.; Graff, G. L.; Li, L.; Hu, J.; Wang, C.; Xiao, J.; Xia, G.; Viswanathan, V. V.; Baskaran, S.; Sprenkle, V.; Li, X.; Shao, Y.; Schwenzer, B., Materials sience and materials chemistry for large scale electrochemical energy storage: From transportation to electrical grid. Adv. Funct. Mater. 2013, 23 (8), 929-946.

4. Palacin, M. R., Recent advances in rechargeable battery materials: A chemist's perspective. Chem. Soc. Rev. 2009, 38 (9), 2565-75.

5. Thackeray, M. M.; Wolverton, C.; Isaacs, E. D., Electrical energy storage for transportation-approaching the limits of, and going beyond, lithium-ion batteries. Energy Environ. Sci. 2012, 5 (7), 7854-7863.

6. Dunn, B.; Kamath, H.; Tarascon, J. M., Electrical energy storage for the grid: A battery of choices. Science 2011, 334 (6058), 928-35.

7. $\quad$ Myung, S.-T.; Amine, K.; Sun, Y.-K., Nanostructured cathode materials for rechargeable lithium batteries. J. Power Sources 2015, 283, 219-236.

8. Deringer, V. L., Modelling and understanding battery materials with machine-learning-driven atomistic simulations. Journal of Physics: Energy 2020, 2 (4), 041003.

9. The Royal Swedish Academy of Sciences (Oct 9, 2019), The Nobel Prize in Chemistry 2019, Retrieved from https://www.nobelprize.org/prizes/chemistry/2019/pressrelease.

10. Zhong, R., Tesla to investigate car that appeared to burst Into flames in Shanghai. The New York Times April 22nd, 2019. 
11. Mouawad, J., Report on Boeing 787 Dreamliner battery flaws finds lapses at multiple points. The New York Times December 1st, 2014.

12. Oliveira, L.; Messagie, M.; Rangaraju, S.; Sanfelix, J.; Rivaz, M. H.; van Mierlo, J., Key issues of lithium-ion batteries from resource depletion to environmental performance indicators. J. Clean. Prod. A 2015, 108, 354-362.

13. Nkulu, C. B. L.; Casas, L.; Haufroid, V.; De Putter, T.; Saenen, N. D.; Kayembe-Kitenge, T.; Obadia, P. M.; Mukoma, D. K. W.; Ilunga, J.-M. L.; Nawrot, T. S.; Numbi, O. L.; Smolders, E.; Nemery, B., Sustainability of artisanal mining of cobalt in DR Congo. Nat. Sustain. 2018, 1, 495-504.

14. Budnyak, T. M.; Slabon, A.; Sipponen, M. H., Lignininorganic interfaces: Chemistry and applications from adsorbents to catalysts and energy storage materials. ChemSusChem 2020, 13 (17), 4344-4355.

15. Lin, D.; Liu, Y.; Cui, Y., Reviving the lithium metal anode for high-energy batteries. Nature Nanotechnol. 2017, 12 (3), 194-206.

16. Bodansky, D., Nuclear energy: Principles, practices, and prospects. Springer-Verlag: New York, 2010.

17. Breeze, P., Nuclear power. Elsevier, 2017.

18. Whittingham, M. S., Lithium batteries and cathode materials. Chem. Rev. 2004, 104 (10), 4271-4302.

19. Masquelier, C.; Croguennec, L., Polyanionic (phosphates, silicates, sulfates) frameworks as electrode materials for rechargeable Li (or Na) batteries. Chem. Rev. 2013, 113 (8), 6552-91.

20. Armand, M.; Tarascon, J. M., Building better batteries Nature 2008, 451 (7179), 652-7.

21. Bruce, P. G., Energy storage beyond the horizon: Rechargeable lithium batteries. Solid State Ionics 2008, 179 (2126), 752-760.

22. Bruce, P. G.; Freunberger, S. A.; Hardwick, L. J.; Tarascon, J. M., $\mathrm{Li}-\mathrm{O}_{2}$ and $\mathrm{Li}-\mathrm{S}$ batteries with high energy storage. Nat Mater 2012, 11 (1), 19-29.

23. Park, M.; Zhang, X.; Chung, M.; Less, G. B.; Sastry, A. M. A review of conduction phenomena in Li-ion batteries. J. Power Sources 2010, 195 (24), 7904-7929.

24. Scrosati, B.; Garche, J., Lithium batteries: Status, prospects and future. J. Power Sources 2010, 195 (9), 2419-2430. 25. Scrosati, B.; Hassoun, J.; Sun, Y.-K., Lithium-ion batteries. A look into the future. Energy Environ. Sci. 2011, 4 (9), 3287-3295.

26. Goodenough, J. B., Cathode materials: A personal perspective. J. Power Sources 2007, 174 (2), 996-1000.

27. Goodenough, J. B.; Kim, Y., Challenges for rechargeable Li batteries. Chem. Mater. 2010, 22 (3), 587-603.

28. Goodenough, J. B.; Park, K. S., The Li-ion rechargeable battery: A perspective. J. Am. Chem. Soc. 2013, 135 (4), 1167-76.

29. Zaghib, K.; Guerfi, A.; Hovington, P.; Vijh, A.; Trudeau, M.; Mauger, A.; Goodenough, J. B.; Julien, C. M., Review and analysis of nanostructured olivine-based lithium recheargeable batteries: Status and trends. J. Power Sources 2013, 232, 357369.

30. Etacheri, V.; Marom, R.; Elazari, R.; Salitra, G.; Aurbach, D., Challenges in the development of advanced Li-ion batteries: a review. Energy Environ. Sci. 2011, 4 (9), 3243-3262.

31. Takada, K., Progress and prospective of solid-state lithium batteries. Acta Mater. 2013, 61 (3), 759-770.

32. Gong, Z.; Yang, Y., Recent advances in the research of polyanion-type cathode materials for Li-ion batteries. Energy Environ. Sci. 2011, 4 (9), 3223-3242.

33. Fergus, J. W., Recent developments in cathode materials for lithium ion batteries. J. Power Sources 2010, 195 (4), 939954.

34. Fergus, J. W., Ion transport in sodium ion conducting solid electrolytes. Solid State Ionics 2012, 227, 102-112.

35. Ellis, B. L.; Lee, K. T.; Nazar, L. F., Positive electrode materials for Li-ion and Li-batteries. Chem. Mater. 2010, 22 (3), 691-714.

36. Ellis, B. L.; Nazar, L. F., Sodium and sodium-ion energy storage batteries. Curr. Opin. Solid State Mater. Sci. 2012, 16 (4), 168-177.

37. Xu, B.; Qian, D.; Wang, Z.; Meng, Y. S., Recent progress in cathode materials research for advanced lithium ion batteries. Mater. Sci. Eng. R 2012, 73 (5-6), 51-65.

38. He, P.; Yu, H.; Li, D.; Zhou, H., Layered lithium transition metal oxide cathodes towards high energy lithium-ion batteries. J. Mater. Chem. 2012, 22 (9), 3680-3695.

39. Kim, S.-W.; Seo, D.-H.; Ma, X.; Ceder, G.; Kang, K., Electrode materials for rechargeable sodium-ion batteries: Potential alternatives to current lithium-ion batteries. $A d v$. Energy Mater. 2012, 2 (7), 710-721.

40. $\quad$ Palomares, V.; Serras, P.; Villaluenga, I.; Hueso, K. B.; Carretero-González, J.; Rojo, T., Na-ion batteries, recent advances and present challenges to become low cost energy storage systems. Energy Environ. Sci. 2012, 5 (3), 5884-5901.

41. Slater, M. D.; Kim, D.; Lee, E.; Johnson, C. S., Sodium-ion batteries. Adv. Funct. Mater. 2013, 23 (8), 947-958.

42. Ponrouch, A.; Dedryvère, R.; Monti, D.; Demet, A. E.; Ateba Mba, J. M.; Croguennec, L.; Masquelier, C.; Johansson, P.; Palacín, M. R., Towards high energy density sodium ion batteries through electrolyte optimization. Energy Environ. Sci. 2013, 6 (8), 2361-2369.

43. Pan, H.; Hu, Y.-S.; Chen, L., Room-temperature stationary sodium-ion batteries for large-scale electric energy storage. Energy Environ. Sci. 2013, 6 (8), 2338-2360.

44. $\quad$ Fan, L.; Ma, R.; Zhang, Q.; Jia, X.; Lu, B., Graphite anode for a potassium-ion battery with unprecedented performance. Angew. Chem. Int. Ed. 2019, 58 (31), 10500-10505.

45. Lenchuk, O.; Adelhelm, P.; Mollenhauer, D., New insights into the origin of unstable sodium graphite intercalation compounds. Phys. Chem. Chem. Phys. 2019, 21 (35), 1937819390.

46. Li, Y.; Lu, Y.; Adelhelm, P.; Titirici, M.-M.; Hu, Y.-S., Intercalation chemistry of graphite: Alkali metal ions and beyond. Chem. Soc. Rev. 2019, 48 (17), 4655-4687.

47. Kubota, K.; Dahbi, M.; Hosaka, T.; Kumakura, S.; Komaba, S., Towards K-ion and Na-ion batteries as "Beyond Liion". Chem. Rec. 2018, 18 (4), 459-479.

48. Wang, Z.; Selbach, S. M.; Grande, T., Van der Waals density functional study of the energetics of alkali metal intercalation in graphite. RSC Adv. 2014, 4 (8), 4069-4079.

49. Kim, H.; Yoon, G.; Lim, K.; Kang, K., A comparative study of graphite electrodes using the co-intercalation phenomenon for rechargeable $\mathrm{Li}, \mathrm{Na}$ and $\mathrm{K}$ batteries. Chem. Commun. 2016, 52 (85), 12618-12621.

50. Wu, Y. P.; Rahm, E.; Holze, R., Carbon anode materials for lithium ion batteries. J. Power Sources 2003, 114 (2), 228236.

51. Kaskhedikar, N. A.; Maier, J., Lithium storage in carbon nanostructures. Adv. Mater. 2009, 21 (25-26), 2664-2680.

52. Nitta, N.; Wu, F.; Lee, J. T.; Yushin, G., Li-ion battery materials: Present and future. Mat. Today 2015, 18 (5), 252-264. 
53.

Irisarri, E.; Ponrouch, A.; Palacin, M. R., Review-Hard carbon negative electrode materials for sodium-ion batteries. $J$. Electrochem. Soc. 2015, 162 (14), A2476-A2482.

54. Huang, J.-X.; Csányi, G.; Zhao, J.-B.; Cheng, J.; Deringer, V. L., First-principles study of alkali-metal intercalation in disordered carbon anode materials. J. Mater. Chem. A 2019, 7 (32), 19070-19080.

55. Thomas, M.; Bruce, P.; Goodenough, J., Lithium mobility in the layered oxide $\mathrm{Li}_{1-\mathrm{x}} \mathrm{CoO}_{2}$. Solid State Ionics 1985, 17 (1), 1319.

56. Mizushima, K.; Jones, P. C.; Wiseman, P. J.; Goodenough, J. B., $\mathrm{Li}_{\mathrm{x}} \mathrm{CoO}_{2}(0<\mathrm{x}<1)$ : A new cathode material for batteries of high energy density. Mater. Res. Bull. 1980, 15 (6), 783-789.

57. Guo, S.; Sun, Y.; Yi, J.; Zhu, K.; Liu, P.; Zhu, Y.; Zhu, G.z.; Chen, M.; Ishida, M.; Zhou, H., Understanding sodium-ion diffusion in layered P2 and P3 oxides via experiments and firstprinciples calculations: A bridge between crystal structure and electrochemical performance. NPG Asia Mater. 2016, 8 (4), e266. 58. Liang, M.; Zhi, L., Graphene-based electrode materials for rechargeable lithium batteries. J. Mater. Chem. 2009, 19 (33), 5871-5878.

59. Liu, Y.; Merinov, B. V.; Goddard, W. A., 3rd, Origin of low sodium capacity in graphite and generally weak substrate binding of $\mathrm{Na}$ and $\mathrm{Mg}$ among alkali and alkaline earth metals. Proc. Natl. Acad. Sci. U. S. A. 2016, 113 (14), 3735-9.

60. Deringer, V. L.; Merlet, C.; Hu, Y.; Lee, T. H.; Kattirtzi, J. A.; Pecher, O.; Csanyi, G.; Elliott, S. R.; Grey, C. P., Towards an atomistic understanding of disordered carbon electrode materials. Chem. Commun. 2018, 54 (47), 5988-5991.

61. Bonaccorso, F.; Colombo, L.; Yu, G.; Stoller, M.; Tozzini, V.; Ferrari, A. C.; Ruoff, R. S.; Pellegrini, V., 2D materials. graphene, related two-dimensional crystals, and hybrid systems for energy conversion and storage. Science 2015, 347 (6217), 1246501.

62. Eguía-Barrio, A.; Castillo-Martínez, E.; Liu, X.; Dronskowski, R.; Armand, M.; Rojo, T., Carbodiimides: New materials applied as anode electrodes for sodium and lithium ion batteries. J. Mater. Chem. A 2016, 4 (5), 1608-1611.

63. Shi, P.; Li, T.; Zhang, R.; Shen, X.; Cheng, X. B.; Xu, R.; Huang, J. Q.; Chen, X. R.; Liu, H.; Zhang, Q., Lithiophilic LiC 6 layers on carbon hosts enabling stable Li metal anode in working batteries. Adv. Mater. 2019, 31 (8), 1807131.

64. Ohzuku, T.; Iwakoshi, Y.; Sawai, K., Formation of lithiumgraphite intercalation compounds in nonaqueous electrolytes and their application as a negative electrode for a lithium ion (shuttlecock) cell. J. Electrochem. Soc. 1993, 140 (9), 2490-2498. 65. Dronskowski, R.; Chen, K.; Fehse, M.; Laurita, A.; Arayamparambil, J. J.; Sougrati, M. T.; Stievano, L., Quantumchemical study of the FeNCN conversion-reaction mechanism in lithium- and sodium-ion batteries. Angew. Chem. Int. Ed. 2019, 59 (9), 3718- 3723.

66. Sougrati, M. T.; Darwiche, A.; Liu, X.; Mahmoud, A.; Hermann, R. P.; Jouen, S.; Monconduit, L.; Dronskowski, R.; Stievano, L., Transition-metal carbodiimides as molecular negative electrode materials for lithium- and sodium-ion batteries with excellent cycling properties. Angew. Chem. Int. Ed 2016, 55 (16), 5090-5.

67. Holzwarth, N.; Rabii, S.; Girifalco, L., Theoretical study of lithium graphite. I. Band structure, density of states, and Fermi-surface properties. Phys. Rev. B 1978, 18 (10), 5190-5205. 68. Holzwarth, N.; Girifalco, L.; Rabii, S., Theoretical study of lithium graphite. II. Spatial distribution of valence electrons. Phys. Rev. B 1978, 18 (10), 5206-5216.

69. DiVincenzo, D.; Holzwarth, N.; Rabii, S., The electronic structure of $\mathrm{KC}_{8}$. Physica $B+C$ 1980, 99, 406-410.
70. Holzwarth, N.; Louie, S. G.; Rabii, S., Lithiumintercalated graphite: Self-consistent electronic structure for stages one, two, and three. Phys. Rev. B 1983, 28 (2), 1013-1025. 71. Ceder, G., Opportunities and challenges for firstprinciples materials design and applications to Li battery materials. MRS Bull. 2011, 35 (9), 693-701.

72. Harding, J. H., Computer simulation of defects in ionic solids. Rep. Prog. Phys. 1990, 53 (11), 1403-1466.

73. Meng, Y. S.; Arroyo-de Dompablo, M. E., Recent advances in first principles computational research of cathode materials for lithium-ion batteries. Acc. Chem. Res. 2013, 46 (5), 1171-80.

74. Meng, Y. S.; Arroyo-de Dompablo, M. E., First principles computational materials design for energy storage materials in lithium ion batteries. Energy Environ. Sci. 2009, 2 (6), 589-609.

75. Catlow, C. R.; Guo, Z. X.; Miskufova, M.; Shevlin, S. A.; Smith, A. G.; Sokol, A. A.; Walsh, A.; Wilson, D. J.; Woodley, S. M., Advances in computational studies of energy materials. Philos. Trans. A Math. Phys. Eng. Sci. 2010, 368 (1923), 3379-456.

76. Walsh, A.; Sokol, A. A.; Catlow, C. R. A., Computational approaches to energy materials. 2013.

77. Catlow, C. R. A., Computer modeling in inorganic crystallography. Elsevier: 1997.

78. Zhou, F.; Cococcioni, M.; Marianetti, C. A.; Morgan, D.; Ceder, G., First-principles prediction of redox potentials in transition-metal compounds with LDA $+U$. Phys. Rev. B: Condens. Matter Mater. Phys. 2004, 70 (23), 235121.

79. Anisimov, V. V.; Zaanen, J.; Andersen, O. K., Band theory and Mott insulators: Hubbard $U$ instead of Stoner I. Phys. Rev. B: Condens Matter Mater. Phys. 1991, 44 (3), 943-954.

80. Liechtenstein, A. I.; Anisimov, V. V.; Zaanen, J., Densityfunctional theory and strong interactions: Orbital ordering in Mott-Hubbard insulators. Phys. Rev. B: Condens Matter Mater. Phys. 1995, 52 (8), R5467-R5470.

81. Löwdin, P. O., On the non-orthogonality problem connected with the use of atomic wave functions in the theory of molecules and crystals. J. Chem. Phys. 1950, 18, 365-375.

82. Mulliken, R. S., Electronic population analysis on LCAOMO molecular wave functions. I. J. Chem. Phys. 1955, 23, 18331840 .

83. Ertural, C.; Steinberg, S.; Dronskowski, R., Development of a robust tool to extract Mulliken and Löwdin charges from plane waves and its application to solid-state materials. RSC Adv. 2019, 9 (51), 29821-29830.

84. Li, W.-L.; Ertural, C.; Bogdanovski, D.; Li, J.; Dronskowski, R., Chemical bonding of crystalline $\mathrm{LnB}_{6}$ ( $\mathrm{Ln}=\mathrm{La}-$ $\mathrm{Lu}$ ) and its relationship with $\mathrm{Ln}_{2} \mathrm{~B}_{8}$ gas-phase complexes. Inorg. Chem. 2018, 57, 12999-13008.

85. Nelson, R.; Ertural, C.; George, J.; Deringer, V. L.; Hautier, G.; Dronskowski, R., LOBSTER: Local orbital projections, atomic charges, and chemical-bonding analysis from projectoraugmented-wave-based density-functional theory. J. Comput. Chem. 2020, 41 (21), 1931-1940.

86. Sougrati, M. T.; Arayamparambil, J. J.; Liu, X.; Mann, M.; Slabon, A.; Stievano, L.; Dronskowski, R., Carbodiimides as energy materials: Which directions for a reasonable future? Dalton Trans. 2018, 47 (32), 10827-10832.

87. Mann, M.; Reckeweg, O.; Dronskowski, R., Synthesis and characterization of the new dicyanamide $\mathrm{LiCs}_{2}\left[\mathrm{~N}(\mathrm{CN})_{2}\right]_{3}$. Inorganics 2018, 6 (4), 108.

88. Corkett, A. J.; Dronskowski, R., A new tilt and an old twist on the nickel arsenide structure-type: Synthesis and characterisation of the quaternary transition-metal cyanamides $\mathrm{A}_{2} \mathrm{MnSn}_{2}(\mathrm{NCN})_{6}(\mathrm{~A}=\mathrm{Li}$ and $\mathrm{Na})$. Dalton Trans. 2019, 48 (40), 15029-15035. 
89.

Chen, K.; Dronskowski, R., First-principles study of divalent $3 \mathrm{~d}$ transition-metal carbodiimides. J. Phys. Chem. A 2019, 123 (43), 9328-9335.

90. Ressnig, D.; Shalom, M.; Patscheider, J.; Moré, R.; Evangelisti, F.; Antonietti, M.; Patzke, G. R., Photochemical and electrocatalytic water oxidation activity of cobalt carbodiimide. $J$. Mater. Chem. A 2015, 3 (9), 5072-5082.

91. Maintz, S.; Deringer, V. L.; Tchougréeff, A. L.; Dronskowski, R., Analytic projection from plane-wave and PAW wavefunctions and application to chemical-bonding analysis in solids. J. Comput. Chem. 2013, 34, 2557-2567.

92. Maintz, S.; Deringer, V. L.; Tchougréeff, A. L.; Dronskowski, R., LOBSTER: A tool to extract chemical bonding from plane-wave based DFT. J. Comput. Chem. 2016, 37, 10301035.

93. Zewdie, G. M.; Zhou, Y.; Sun, L.; Rao, F.; Deringer, V. L.; Mazzarello, R.; Zhang, W., Chemical design principles for cachetype $\mathrm{Sc}-\mathrm{Sb}-\mathrm{Te}$ phase-change memory materials. Chem. Mater. 2019, 31 (11), 4008-4015.

94. Konze, P. M.; Dronskowski, R.; Deringer, V. L., Exploring chemical bonding in phase-change materials with orbital-based indicators. Phys. Status Solidi RRL 2019, 13 (4), 1800579.

95. Bader, R. F. W., A quantum theory of molecular structure and its applications. Chem. Rev. 1991, 91, 893-928.

96. Bader, R. F. W., Atoms in molecules: A quantum theory. Oxford University Press, Oxford, 1994.

97. Henkelman, G.; Arnaldsson, A.; Jónsson, H., A fast and robust algorithm for Bader decomposition of charge density. Comput. Mater. Sci. 2006, 36, 354-360.

98. Sanville, E.; Kenny, S. D.; Smith, R.; Henkelman, G., An improved grid-based algorithm for Bader charge allocation. $J$. Comp. Chem. 2007, 28, 899-908.

99. Tang, W.; Sanville, E.; Henkelman, G., A grid-based Bader analysis algorithm without lattice bias. J. Phys. Condens. Matter 2009, 21, 084204.

100. Yu, M.; Trinkle, D. R., Accurate and efficient algorithm for Bader charge integration. J. Chem. Phys. 2011, 134, 064111.

101. Kresse, G.; Furthmüller, J., Efficiency of ab-initio total energy calculations for metals and semiconductors using a planewave basis set. Comput. Mater. Sci. 1996, 6, 15-50.

102. Kresse, G.; Furthmüller, J., Efficient iterative schemes for $a b$ initio total-energy calculations using a plane-wave basis set. Phys. Rev. B: Condens. Matter Mater. Phys. 1996, 54, 1116911186.

103. Kresse, G.; Hafner, J., Ab initio molecular dynamics for liquid metals. Phys. Rev. B: Condens. Matter Mater. Phys. 1993, 47 (1), 558-561.

104. Kresse, G.; Joubert, D., From ultrasoft pseudopotentials to the projector augmented-wave method. Phys. Rev. B: Condens. Matter Mater. Phys. 1999, 59, 1758-1775.

105. Kresse, G.; Marsman, M.; Furthmüller, J., Vienna Ab Initio Simulation Package (VASP), The Guide. Computational Materials Physics, Faculty of Physics, Universität Wien: Vienna, Austria, 2014

106. Perdew, J. P.; Burke, K.; Ernzerhof, M., Generalized gradient approximation made simple. Phys. Rev. Lett. 1996, 77, 3865-3868

107. van Elp, J.; Wieland, J. L.; Eskes, H.; Kuiper, P.; Sawatzky G. A.; de Groot, F. M.; Turner, T. S., Electronic structure of CoO, Lidoped CoO, and LiCoO 2 . Phys. Rev. B: Condens Matter Mater. Phys. 1991, 44 (12), 6090-6103.

108. Zhou, F.; Kang, K.; Maxisch, T.; Ceder, G.; Morgan, D., The electronic structure and band gap of $\mathrm{LiFePO}_{4}$ and $\mathrm{LiMnPO}_{4}$. Solid State Commun. 2004, 132 (3-4), 181-186.
109. Nakayama, M.; Yamada, S.; Jalem, R.; Kasuga, T., Density functional studies of olivine-type $\mathrm{LiFePO}_{4}$ and $\mathrm{NaFePO}_{4}$ as positive electrode materials for rechargeable lithium and sodiumion batteries. Solid State Ionics 2016, 286, 40-44.

110. Hertz, J. T.; Huang, Q.; McQueen, T.; Klimczuk, T.; Bos, J. W. G.; Viciu, L.; Cava, R. J., Magnetism and structure of $\mathrm{Li}_{\mathrm{x}} \mathrm{CoO}_{2}$ and comparison to $\mathrm{Na}_{x} \mathrm{CoO}_{2}$. Phys. Rev. B: Condens. Matter Mater. Phys. 2008, 77 (7), 075119.

111. Santoro, R. P.; Newnham, R. E., Antiferromagnetism in LiFePO4. Acta Crystallogr. 1967, 22 (3), 344-347.

112. Arcelus, 0.; Nikolaev, S.; Carrasco, J.; Solovyev, I., Magnetism of $\mathrm{NaFePO}_{4}$ and related polyanionic compounds. Phys. Chem. Chem. Phys. 2018, 20 (19), 13497-13507.

113. Avdeev, M.; Mohamed, Z.; Ling, C. D.; Lu, J.; Tamaru, M.; Yamada, A.; Barpanda, P., Magnetic structures of $\mathrm{NaFePO}_{4}$ maricite and triphylite polymorphs for sodium-ion batteries. Inorg. Chem. 2013, 52 (15), 8685-93.

114. Grimme, S.; Ehrlich, S.; Goerigk, L., Effect of the damping function in dispersion corrected density functional theory. J. Comp. Chem. 2011, 32 (7), 1456-1465.

115. Grimme, S.; Antony, J.; Ehrlich, S.; Krieg, H., A consistent and accurate $a b$ initio parametrization of density functional dispersion correction (DFT-D) for the 94 elements H-Pu. J. Chem. Phys. 2010, 132 (15), 154104.

116. Becke, A. D.; Johnson, E. R., A density-functional model of the dispersion interaction. J. Chem. Phys. 2005, 123 (15), 154101.

117. Togo, A.; Tanaka, I., First principles phonon calculations in materials science. Scr. Mater. 2015, 108, 1-5.

118. Sun, J.; Ruzsinszky, A.; Perdew, J. P., Strongly constrained and appropriately normed semilocal density functional. Phys. Rev. Lett. 2015, 115 (3), 036402.

119. Monkhorst, H. J.; Pack, J. D., Special points for Brillouinzone integrations. Phys. Rev. B: Condens. Matter Mater. Phys. 1976, 13, 5188-5192.

120. Kang, K.; Ceder, G., Factors that affect Li mobility in layered lithium transition metal oxides. Phys. Rev. B: Condens Matter Mater. Phys. 2006, 74 (9), 094105.

121. Morgan, D.; Van der Ven, A.; Ceder, G., Li conductivity in $\mathrm{Li}_{\mathrm{x}} \mathrm{MPO}_{4}(\mathrm{M}=\mathrm{Mn}, \mathrm{Fe}, \mathrm{Co}, \mathrm{Ni})$ olivine materials. Electrochem. Solid-State Lett. 2004, 7 (2), A30-A32.

122. Tripathi, R.; Wood, S. M.; Islam, M. S.; Nazar, L. F., Naion mobility in layered $\mathrm{Na}_{2} \mathrm{FePO}_{4} \mathrm{~F}$ and olivine $\mathrm{Na}[\mathrm{Fe}, \mathrm{Mn}] \mathrm{PO}_{4}$. Energy Environ. Sci. 2013, 6 (8), 2257-2264.

123. Okubo, M.; Tanaka, Y.; Zhou, H.; Kudo, T.; Honma, I., Determination of activation energy for $\mathrm{Li}$ ion diffusion in electrodes. J. Phys. Chem. B 2009, 113 (9), 2840-7.

124. Liu, Q.; Li, S.; Wang, S.; Zhang, X.; Zhou, S.; Bai, Y.; Zheng, J.; Lu, X., Kinetically determined phase Transition from stage II $\left(\mathrm{LiC}_{12}\right)$ to stage I $\left(\mathrm{LiC}_{6}\right)$ in a graphite anode for $\mathrm{Li}$-ion batteries. J. Phys. Chem. Lett. 2018, 9 (18), 5567-5573.

125. Hu, B.; Tao, G., Molecular dynamics simulations on lithium diffusion in $\mathrm{LiFePO}_{4}$ : The effect of anti-site defects. $J$. Mater. Chem. A 2015, 3 (40), 20399-20407.

126. Molenda, J.; Kulka, A.; Milewska, A.; Zajac, W.; Swierczek, K., Structural, transport and electrochemical properties of $\mathrm{LiFePO}_{4}$ substituted in lithium and iron sublattices (Al, Zr, W, Mn, Co and Ni). Materials (Basel) 2013, 6 (5), 16561687.

127. Tealdi, C.; Heath, J.; Islam, M. S., Feeling the strain: Enhancing ionic transport in olivine phosphate cathodes for $\mathrm{Li}$ and Na-ion batteries through strain effects. J. Mater. Chem. A 2016, 4 (18), 6998-7004. 
128. Toyoura, K.; Koyama, Y.; Kuwabara, A.; Tanaka, I., Effects of off-stoichiometry of $\mathrm{LiC}_{6}$ on the lithium diffusion mechanism and diffusivity by first principles calculations. J. Phys. Chem. C 2010, 114 (5), 2375-2379.

129. Adams, S.; Rao, R. P., Simulated defect and interface engineering for high power Li electrode materials. Solid State Ionics 2011, 184, 57-61.

130. Stoffel, R. P.; Wessel, C.; Lumey, M. W.; Dronskowski, R., $\mathrm{Ab}$ initio thermochemistry of solid-state materials. Angew. Chem. Int. Ed. 2010, 49 (31), 5242-66.

131. Jónsson, H.; Mills, G.; Jacobsen, K. W., Nudged elastic band method for finding minimum energy paths of transitions. In Classical and Quantum Dynamics in Condensed Phase Simulations, World Scientific: Singapore, 1998.

132. Eck, B., wxDragon, version 2.2.3, 1994-2020. RWTH Aachen, Aachen, Germany

133. Ni, K.; Wang, X.; Tao, Z.; Yang, J.; Shu, N.; Ye, J.; Pan, F.; Xie, J.; Tan, Z.; Sun, X.; Liu, J.; Qi, Z.; Chen, Y.; Wu, X.; Zhu, Y., In Operando probing of lithium-ion storage on single-layer graphene. Adv. Mater. 2019, 31 (23), e1808091.

134. Rao, F.; Wang, Z.; Xu, B.; Chen, L.; Ouyang, C., Firstprinciples study of lithium and sodium atoms intercalation in fluorinated graphite. Engineering 2015, 1 (2), 243-246.

135. Bachrach, S. M., Population analysis and electron densities from quantum mechanics. In Reviews in computational chemistry, Lipkowitz, K. B.; Boyd, D. B., Eds. VCH Publishers, Inc.: New York, Weinheim, Cambridge, 1994; Vol. 5, pp 171-228.

136. Douakha, N.; Holzapfel, M.; Chappel, E.; Chouteau, G.; Croguennec, L.; Ott, A.; Ouladdiaf, B., Nuclear and magnetic structure of layered $\mathrm{Li} \mathrm{Fe} 1-\mathrm{x} \mathrm{Co}_{\mathrm{x}} \mathrm{O}_{2}(0<=\mathrm{x}<=1)$ determined by highresolution neutron diffraction. J. Solid State Chem. 2002, 163, 406-411.

137. Zhang, P.; Wen, Y.; Liu, J.; Xu, Q.; Ren, X.; Zhang, Q., Performance and structure of $\mathrm{Mg}^{2+}$ doped lithium iron phosphate prepared by chemical precipitation method. Gongneng Cailiao/J. Funct. Mater. 2006, 37, 1942-5.

138. Pauling, L., The nature of the chemical bond: IV. The Energy of single bonds and the relative electronegativity of atoms. J. Am. Chem. Soc. 1932, 54, 3570-3582.

139. Dolotko, O.; Senyshyn, A.; Mühlbauer, M. J.; Nikolowski, $\mathrm{K}$.; Ehrenberg, $\mathrm{H}$., Understanding structural changes in $\mathrm{NMC} \mathrm{Li-}$ ion cells by in situ neutron diffraction. J. Power Sources 2014, 255 197-203.

140. Thinius, S.; Islam, M. M.; Heitjans, P.; Bredow, T., Theoretical study of $\mathrm{Li}$ migration in lithium-graphite intercalation compounds with dispersion-corrected DFT methods. J. Phys. Chem. C 2014, 118 (5), 2273-2280.

141. Stevens, D. A.; Dahn, J. R., An in situ small-angle X-ray scattering study of sodium insertion into a nanoporous carbon anode material within an operating electrochemical cell. $J$. Electrochem. Soc. 2000, 147 (12), 4428-4431.

142. Stevens, D. A.; Dahn, J. R., High capacity anode materials for rechargeable sodium-ion batteries. J. Electrochem. Soc. 2000, 147 (4), 1271-1273.

143. Letellier, M.; Chevallier, F.; Clinard, C.; Frackowiak, E.; Rouzaud, J.-N.; Béguin, F.; Morcrette, M.; Tarascon, J.-M., The first in situ ${ }^{7} \mathrm{Li}$ nuclear magnetic resonance study of lithium insertion in hard-carbon anode materials for Li-ion batteries. J. Chem. Phys. 2003, 118 (13), 6038-6045.

144. Stratford, J. M.; Allan, P. K.; Pecher, O.; Chater, P. A.; Grey, C. P., Mechanistic insights into sodium storage in hard carbon anodes using local structure probes. Chem. Commun. 2016, 52 (84), 12430-12433.
145. Reckeweg, 0.; DiSalvo, F. J.; Schulz, A.; Blaschkowski, B.; Jagiella, S.; Schleid, T., Synthesis, crystal structure, and vibrational spectra of the anhydrous lithium dicyanamide $\mathrm{Li}\left[\mathrm{N}(\mathrm{CN})_{2}\right.$ ]. Z. Anorg. Allg. Chem. 2014, 640 (5), 851-855.

146. Jürgens, B.; Irran, E.; Schneider, J.; Schnick, W., Trimerization of $\mathrm{NaC}_{2} \mathrm{~N}_{3}$ to $\mathrm{Na}_{3} \mathrm{C}_{6} \mathrm{~N}_{9}$ in the solid: $A b$ initio crystal structure determination of two polymorphs of $\mathrm{NaC}_{2} \mathrm{~N}_{3}$ and of $\mathrm{Na}_{3} \mathrm{C}_{6} \mathrm{~N}_{9}$ from X-ray powder diffractometry. Inorg. Chem. 2000, $39(4), 665-70$.

147. Jürgens, B.; Milius, W.; Morys, P.; Schnick, W., Trimerisierung von Dicyanamid-Ionen $\mathrm{C}_{2} \mathrm{~N}_{3}{ }^{-}$- Ionen im Festkoerper; Synthesen, Kristallstrukturen und Eigenschaften von $\mathrm{NaCs}_{2}\left(\mathrm{C}_{2} \mathrm{~N}_{3}\right)_{3}$ und $\mathrm{Na}_{3} \mathrm{C}_{6} \mathrm{~N}_{9} .3\left(\mathrm{H}_{2} \mathrm{O}\right)$. Z. Anorg. Allg. Chem. 1998, 624, 91-97.

148. Allred, A. L.; Rochow, E. G., A scale of electronegativity based on electrostatic force. J. Inorg. and Nucl. Chem. 1958, 5 (4), 264-268.

149. Islam, M. M.; Bredow, T.; Heitjans, P., The ionic conductivity in lithium-boron oxide materials and its relation to structural, electronic and defect properties: insights from theory. J. Phys. Condens. Matter. 2012, 24 (20), 203201.

150. Yoon, H.; Lane, G. H.; Shekibi, Y.; Howlett, P. C.; Forsyth, M.; Best, A. S.; MacFarlane, D. R., Lithium electrochemistry and cycling behaviour of ionic liquids using cyano based anions. Energy Environ. Sci. 2013, 6 (3), 979-986.

151. Müller, P. C. Quantum chemical descriptors towards materials mapping. Master Thesis, RWTH Aachen, 2019.

152. Liu, X.; Müller, P.; Kroll, P.; Dronskowski, R.; Wilsmann, W.; Conradt, R., Experimental and quantum-chemical studies on the thermochemical stabilities of mercury carbodiimide and mercury cyanamide. ChemPhysChem 2003, 4 (7), 725-731.

153. Liu, X.; Krott, M.; Müller, P.; Hu, C.; Lueken, H.; Dronskowski, R., Synthesis, crystal structure, and properties of MnNCN, the first carbodiimide of a magnetic transition metal. Inorg. Chem. 2005, 44 (9), 3001-3003.

154. Krott, M.; Liu, X.; Fokwa, B. P. T.; Speldrich, M.; Lueken, H.; Dronskowski, R., Synthesis, crystal-structure determination and magnetic properties of two new transition-metal carbodiimides: CoNCN and NiNCN. Inorg. Chem. 2007, 46 (6), 2204-2207.

155. Liu, X.; Decker, A.; Schmitz, D.; Dronskowski, R., Crystal structure refinement of lead cyanamide and the stiffness of the cyanamide anion. Z. anorg. allg. Chem. 2000, 626 (1), 103-105.

156. Corkett, A. J.; Konze, P. M.; Dronskowski, R., Synthesis, crystal structure, and chemical-bonding analysis of BaZn(NCN)2. Inorganics 2018, 6 (1), 1.

157. Allen, F. H.; Kennard, O.; Watson, D. G.; Brammer, L.; Orpen, A. G.; Taylor, R., Tables of bond lengths determined by Xray and neutron diffraction. Part 1 . Bond lengths in organic compounds. J. Chem. Soc. Perkin Trans. II 1987, (12), S1-S19.

158. Grinberg, I.; Yourdshahyan, Y.; Rappe, A. M., CO on Pt (111) puzzle: A possible solution. J. Chem. Phys. 2002, 117 (5), 2264-2270.

159. Benson, S. W., III-Bond energies. J. Chem. Educ. 1965, 42 (9), 502-518.

160. Hioe, J.; Šakić, D.; Vrček, V.; Zipse, H., The stability of nitrogen-centered radicals. Org. Biomol. Chem. 2015, 13 (1), 157169.

161. O'Reilly, R. J.; Karton, A.; Radom, L., N-H and N-Cl homolytic bond dissociation energies and radical stabilization energies: An assessment of theoretical procedures through comparison with benchmark-quality $\mathrm{W} 2 \mathrm{w}$ data. Int. J. Quantum Chem. 2012, 112 (8), 1862-1878. 
162. Ishida, S.; Hirakawa, F.; Iwamoto, T., A stable dialkylphosphinyl radical. J. Am. Chem. Soc. 2011, 133 (33), 12968-12971.

163. Dronskowski, R., Computational Chemistry of Solid State Materials - A Guide for Material Scientists, Chemists, Physicists and others. WILEY-VCH Verlag GmbH \& Co. KGaA:Weinheim, 2005.

164. Nune, S. V. K.; Basaran, A. T.; Ülker, E.; Mishra, R.; Karadas, F., Metal dicyanamides as efficient and robust wateroxidation catalysts. ChemCatChem 2017, 9 (2), 300-307.

165. Nag, A.; Schnick, W., Synthesis, crystal structure and thermal behavior of gadolinium dicyanamide dihydrate $\mathrm{Gd}\left[\mathrm{N}(\mathrm{CN})_{2}\right]_{3} \cdot 2 \mathrm{H}_{2} \mathrm{O}$. Z. anorg. allg. Chem. 2006, 632 (4), 609-614. 166. Liu, X.; Kroll, P.; Dronskowski, R., Crystal structure, magnetic properties, and electronic structure of $\mathrm{Ni}\left(\mathrm{NCNH}_{2}\right)_{4} \mathrm{Cl}_{2}$ and $\mathrm{Co}\left(\mathrm{NCNH}_{2}\right)_{4} \mathrm{Cl}_{2}$. Z. anorg. allg. Chem. 2001, 627 (7), 16821686.

167. Batten, S. R.; Murray, K. S., Structure and magnetism of coordination polymers containing dicyanamide and tricyanomethanide. Coord. Chem. Rev. 2003, 246 (1-2), 103-130.

168. Horvath-Bordon, E.; Kroke, E.; Svoboda, I.; Fuess, H.; Riedel, R., Potassium melonate, $\mathrm{K}_{3}\left[\mathrm{C}_{6} \mathrm{~N}_{7}(\mathrm{NCN})_{3}\right] \cdot 5 \mathrm{H}_{2} \mathrm{O}$, and its potential use for the synthesis of graphite-like $\mathrm{C}_{3} \mathrm{~N}_{4}$ materials. New J. Chem. 2005, 29 (5), 693-699.

169. Hodgson, S. A.; Hunt, S. J.; Sørensen, T. J.; Thompson, A. L.; Reynolds, E. M.; Faulkner, S.; Goodwin, A. L., Anomalous thermal expansion and luminescence thermochromism in silver(I) dicyanamide. Eur. J. Inorg. Chem. 2016, 2016 (27), 43784381.

\section{For Table of Contents Only}

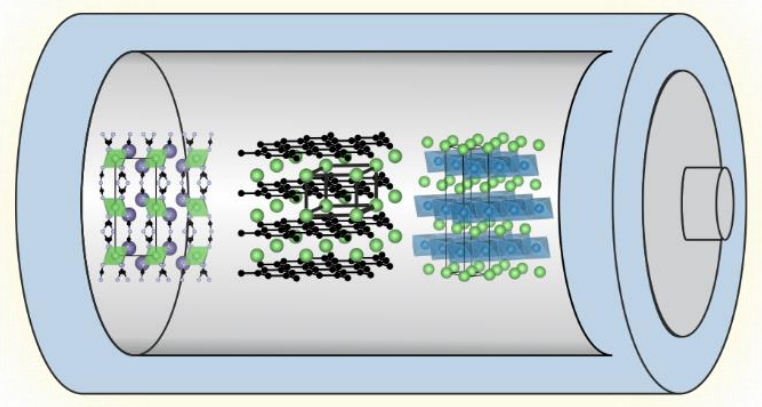

170. Jürgens, B.; Irran, E.; Höppe, H. A.; Schnick, W., Phase transition of a dicyanamide with rutile-like structure: Syntheses and crystal structures of $\alpha$-and $\beta-\mathrm{Cd}\left[\mathrm{N}(\mathrm{CN})_{2}\right]_{2}$. Z. anorg. allg. Chem. 2004, 630 (2), 219-223.

171. Jürgens, B.; Irran, E.; Schnick, W., Syntheses, vibrational spectroscopy, and crystal structure determination from X-ray powder diffraction data of alkaline earth dicyanamides $\mathrm{M}\left[\mathrm{N}(\mathrm{CN})_{2}\right]_{2}$ with $\mathrm{M}=\mathrm{Mg}, \mathrm{Ca}, \mathrm{Sr}$, and Ba. J. Solid State Chem. 2001, 157 (2), 241-249.

172. Jürgens, B.; Höppe, H. A.; Schnick, W., Synthesis, crystal structure, vibrational spectroscopy, and thermal behaviour of lead dicyanamide $\mathrm{Pb}\left[\mathrm{N}(\mathrm{CN})_{2}\right]_{2}$. Solid State Sci. 2002, 4 (6), 821825.

173. Irran, E.; Jürgens, B.; Schnick, W., Trimerization of alkali Dicyanamides $\mathrm{M}\left[\mathrm{N}(\mathrm{CN})_{2}\right]$ and formation of tricyanomelaminates $\mathrm{M}_{3}\left[\mathrm{C}_{6} \mathrm{~N}_{9}\right](\mathrm{M}=\mathrm{K}, \mathrm{Rb})$ in the melt: Crystal structure determination of three polymorphs of $\mathrm{K}\left[\mathrm{N}(\mathrm{CN})_{2}\right]$, two of $\mathrm{Rb}\left[\mathrm{N}(\mathrm{CN})_{2}\right]$, and one of $\mathrm{K}_{3}\left[\mathrm{C}_{6} \mathrm{~N}_{9}\right]$ and $\mathrm{Rb}_{3}\left[\mathrm{C}_{6} \mathrm{~N}_{9}\right]$ from X-ray powder diffractometry. Chem. Eur. J. 2001, 7 (24), 5372-5381.

174. Purdy, A. P.; Houser, E.; George, C. F., Lithium dicyanamide, its reactions with cyanuric chloride, and the crystal structures of $\operatorname{LiN}(\mathrm{CN})_{2}(\mathrm{MeCN})_{2}$ and $\operatorname{LiCN}\left(\mathrm{C}_{5} \mathrm{H}_{5} \mathrm{~N}\right)_{2}$. Polyhedron 1997, 16 (20), 3671-3679.

175. Akimoto, J.; Gotoh, Y.; Oosawa, Y., Synthesis and structure refinement of $\mathrm{LiCoO}_{2}$ single crystals. J. Solid State Chem. 1998, 141, 298-302.
Studying several commonly used and new Li and Na compounds for the utilization as anode and cathode materials in rechargeable batteries with the robust Löwdin population analysis tool and other covalent bonding indicators reveals new insight into the intercalation behavior of these materials. 